\title{
Mitigating Scatter in Mechanical Properties in AISI 410 Fabricated via Arc-Based Additive Manufacturing Process
}

\author{
Sougata Roy ${ }^{1,2, *}$, Benjamin Shassere ${ }^{3}$, Jake Yoder ${ }^{4}$, Andrzej Nycz ${ }^{5}$, Mark Noakes ${ }^{5}$, \\ Badri K. Narayanan ${ }^{6}$, Luke Meyer ${ }^{5}$, Jonathan Paul ${ }^{6}$ and Niyanth Sridharan ${ }^{6}$ \\ 1 Materials Science and Technology Division, Oak Ridge National Laboratory, Oak Ridge, TN 37830, USA; \\ roys1@ornl.gov \\ 2 Mechanical Engineering Department, University of North Dakota, Grand Forks, ND 58202, USA; \\ sougata.roy@und.edu \\ 3 Y-12 National Security Complex, Development Division, Consolidated Nuclear Security, LLC, \\ Oak Ridge, TN 37830, USA; benjamin.shassere@cns.doe.gov \\ 4 Materials Science and Engineering Department, Virginia TechTM, Blacksburg, VA 24061, USA; \\ jkyoder@vt.edu \\ 5 Oak Ridge National Laboratory, Energy and Transport Science and Technology Division, \\ Oak Ridge, TN 37830, USA; nycza@ornl.gov (A.N.); noakesmw@ornl.gov (M.N.); meyerlt@ornl.gov (L.M.) \\ 6 Lincoln Electric Company, Cleveland, OH 44117, USA; Badri_Narayanan@LincolnElectric.com (B.K.N.); \\ Jonathan_Paul@LincolnElectric.com (J.P.); Niyanth_Sridharan@LincolnElectric.in (N.S.) \\ * Correspondence: sougata.roy@und.edu
}

Received: 30 September 2020; Accepted: 26 October 2020; Published: 29 October 2020

check for updates

\begin{abstract}
Wire-based metal additive manufacturing utilizes the ability of additive manufacturing to fabricate complex geometries with high deposition rates (above $7 \mathrm{~kg} / \mathrm{h}$ ), thus finding applications in the fabrication of large-scale components, such as stamping dies. Traditionally, the workhorse materials for stamping dies have been martensitic steels. However, the complex thermal gyrations induced during additive manufacturing can cause the evolution of an inhomogeneous microstructure, which leads to a significant scatter in the mechanical properties, especially the toughness. Therefore, to understand these phenomena, arc-based additive AISI 410 samples were fabricated using robotic gas metal arc welding (GMAW) and were subjected to a detailed characterization campaign. The results show significant scatter in the tensile properties as well as Charpy V-notch impact toughness data, which was then correlated to the microstructural heterogeneity and delta $(\delta)$ ferrite formation. Post-processing (austenitizing and tempering) treatments were developed and an $\sim 70 \%$ reduction in the scatter of tensile data and a four-times improvement in the toughness were obtained. The changes in mechanical properties were rationalized based on the microstructure evolution during additive manufacturing. Based on these, an outline to tailor the composition of "printable" steels for tooling with isotropic and uniform mechanical properties is presented and discussed.
\end{abstract}

Keywords: additive manufacturing; steel; delta ferrite; microstructure; mechanical properties

\section{Introduction}

Additive manufacturing (AM) has gained traction over the years due to its ability to fabricate complex geometries, resulting in a significant reduction in lead times and also simplifying the supply chain [1-4]. This has resulted in a significant interest, from tool manufacturers, in using AM to fabricate near-net-shaped parts to reduce the lead times and minimize the tooling costs of machine dies. The crucial advantages are as follows: (1) shortened lead time, (2) less material waste, (3) improved 
functionality through incorporation of more complex features, (4) customized tooling for lower volume parts, and (5) the potential to use many materials in single parts, which can result in lowered overall costs.

While powder-based techniques have dominated the AM industry, there is a need, specifically from the tool and die manufacturers, to quickly build large components (above $10 \mathrm{~kg}$ ), thus prompting interest in wire-arc-based additive manufacturing [5,6]. However, there are several difficulties when fabricating large scale components using wire-arc-based AM techniques. For example, Nycz et al. [7] demonstrated several key challenges while printing an excavator arm, such as print time, deposition process development, integration of the robotic path, heat management, and consistent material properties.

A range of physics-based design rules, such as overhang constraint, bead morphology, and topology optimization, need to be followed for metal big-area additive manufacturing [8,9]. Hu et al. [10] used an integrated computational and experimental approach on low carbon steel to correlate mechanical properties, microstructure and temperature history for a thin wall printed using wire arc additive manufacturing. Limited studies do exist where $\mathrm{H} 13$ has been used in wire-based AM and other direct energy deposition processes. Ali et al. [11] studied the wire arc additive manufacturing of tool steel using the cold metal transfer (CMT) process. They showed that, by keeping the interpass temperature above the martensite start temperature $\left(\mathrm{M}_{\mathrm{s}}\right)$, a homogeneous hardness level can be achieved along the height of printed samples. Ge et al. [12] deposited a crack-free sample of H13 steel. The sample dimensions were $125 \mathrm{~mm}(\mathrm{~L}) \times 85 \mathrm{~mm}(\mathrm{~W}) \times 47 \mathrm{~mm}(\mathrm{H})$ and were deposited on an $\mathrm{H} 13$ substrate. They reported a scatter in uniaxial tension and hardness, which was attributed to an inconsistent $\delta$ ferrite phase in the overlap zone. However, no study has yet demonstrated the ability to fabricate large-scale ( $>30 \mathrm{~kg}$ ) H13 or other tool steel parts using wire-based AM. Therefore, there is a need to explore other printable alloy steels for tooling. The primary factor that determines the printability of steels is the carbon equivalent. To obtain crack-free prints, the selected material needs to have a low $\mathrm{C}$ equivalent and good machinability in the as-printed state, with the ability to be surface-hardened during post-processing. A material which fulfills these requirements is AISI 410 steel; it is a low-C-content steel that is fairly printable, and the high $\mathrm{Cr}$ content can make surface-hardening treatments, such as nitriding, more effective [13].

Due to the nature of the additive manufacturing process, there are several synergies with welding, and good weldability is a necessary condition for good printability. The following factors affect the weldability of stainless steels, and thus printability.

1. Martensitic stainless steels in general are challenging to weld due to their susceptibility to cracking $[14,15]$. Such steels are also susceptible to three different types of cracking which are briefly described below:

(a) Solidification cracking: Martensitic stainless steels generally solidify as primary ferrite. Increasing the carbon content may result in solidification as austenite, which makes the material more prone to solidification cracking [16].

(b) Reheat cracking: This occurs during post-weld heat treatments or heating of previous passes in multi-pass weldments. Impurities such as sulfur, phosphorous, boron, and copper enhance the chance of reheat cracking in the weldments [17].

(c) Hydrogen-induced cracking: Such cracking depends on multiple factors such as composition, hydrogen content, tensile stress, and microstructure. However, due to the low C content ( 0.08-0.1 wt.\%) of SS410, the problem of hydrogen-induced cracking can be circumvented by application of proper preheat and interpass temperatures [18].

2. Apart from cracking, the major challenge is the scatter in mechanical properties, particularly the toughness of steel samples fabricated using additive manufacturing [19-21]. Previous research has attributed this to the heterogeneity in microstructure during multi-pass welding of steels. Toughness scatter in martensitic steel weldments has specifically been attributed to the presence of $\delta$ ferrite. Carrouge et al. [22] showed that reduction in the $\delta$ ferrite improved the notch toughness, 
even in the as-quenched condition, and upon increasing $\delta$ ferrite content from $2 \%$ to $14 \%$, the ductile-to-brittle transition temperature (DBTT) changed from $-86{ }^{\circ} \mathrm{C}$ to $46^{\circ} \mathrm{C}$. Therefore, it is important to understand the mechanisms of formation of $\delta$ ferrite and microstructure evolution during multi-pass welding of AISI 410 steel. Due to the similarities between multi-pass welding and additive manufacturing, similar microstructures can be expected [4,19-21].

Martensitic steels can undergo three major modes of transformation during weld metal solidification, resulting in two distinct microstructures based on welding settings and other parameters [18]:

Fully martensitic microstructure: $\quad \mathrm{L} \rightarrow \mathrm{L} \quad+\quad \mathrm{Fp} \quad$ (primary ferrite) $\quad(\delta) \rightarrow \mathrm{Fp} \quad(\delta) \rightarrow \mathrm{Fp} \quad(\delta) \quad+$ $\gamma_{\text {Austenite }} \rightarrow \gamma_{\text {Austenite }} \rightarrow$ Martensite. The fusion zones of $11 \%-13 \%$ Cr steel typically solidify with a primary $\delta$ ferrite structure. The $\delta$ ferrite then transforms to $\gamma_{\text {Austenite which, upon cooling, transforms }}$ completely to martensite without any $\delta$-ferrite occurring.

Martensite + ferrite: If significant segregation of $\mathrm{Cr}$, Mo, and $\mathrm{C}$ occur during solidification, a eutectic reaction occurs in which $\mathrm{L} \rightarrow \gamma_{\text {Austenite }}+\delta$ ferrite. Since the eutectic ferrite is rich in ferrite-stabilizing elements, it does not transform to austenite upon further cooling, leading to the formation of residual $\delta$ ferrite. However, it has been shown that this need not always be the case. For instance, Castro and de Cadenent [23] have shown that ferrite can be retained at the original ferrite dendrites due to the incomplete transformation of ferrite to austenite, similar to the formation of skeletal $\delta$ ferrite in austenitic stainless-steel welds.

In multi-pass welding, $\delta$-ferrite can form via a solid-state mechanism in the heat-affected zone while reheating as well. Typically, stainless-steel heat-affected martensitic zones are characterized by five distinct zones:

1. Zone 1: The partially melted zone where incipient melting occurs. The temperature in this zone is above the solidus temperature of the material.

2. Zone 2: Here, the room temperature microstructure transforms completely to $\delta$ ferrite with significant grain growth, also called the coarse grain heat-affected zone.

3. Zone 3: This zone is a two-phase region which is characterized by the presence of both austenite and $\delta$ ferrite.

4. Zone 4: The peak temperature is above the upper critical temperature where the room temperature microstructure is completely austenitic

5. Zone 5: The temperature is in the inter-critical region where different fractions of martensite and austenite form depending on the peak temperature.

Zones 1-3 are the high-temperature regions where a significant fraction of non-equilibrium $\delta$ ferrite occurs [22].

In martensitic stainless steels, post-weld heat treatments (PWHT) are normally used to eliminate the $\delta$ ferrite, recover the mechanical properties, and reset the microstructure $[24,25]$. Typically, PWHT are restricted to only tempering operations in which the welds are tempered between $450-750{ }^{\circ} \mathrm{C}$ for times ranging between $30 \mathrm{~min}$ to $2 \mathrm{~h}[18,26]$. Selection of the ideal tempering cycle is critical to achieve a balance between hardness and toughness and to avoid any drastic decreases in toughness due to embrittlement. For example, a $157 \mathrm{~J}$ difference in toughness has been documented in two samples subjected to two different heat treatment cycles. The toughness of the weld metal after being subjected to $650{ }^{\circ} \mathrm{C}-2 \mathrm{~h}+600^{\circ} \mathrm{C}-4 \mathrm{~h}$ was $170 \mathrm{~J}$, as opposed to $13 \mathrm{~J}$ from a weld metal subjected to a tempering cycle of $675{ }^{\circ} \mathrm{C}$ and $615^{\circ} \mathrm{C}$. This difference in the toughness was attributed to the diffusion of $\mathrm{Ni}$ and $\mathrm{C}$ to the retained austenite during tempering at $675^{\circ} \mathrm{C}$, thus stabilizing the austenite films. Upon cooling down below room temperature (RT), the austenite films transform to fresh martensite, leading to a significant drop in toughness [27]. In addition, a systematic study has shown a sharp drop in toughness while tempering the steel between 500 and $650{ }^{\circ} \mathrm{C}$, which was attributed the segregation of phosphorus, and other tramp elements, to the grain boundaries and thus embrittling the steel [28]. 
Chakraborty et al. also documented a similar observation where the toughness dropped from $60 \mathrm{~J}$ to $20 \mathrm{~J}$ while tempering at a range of $450-550{ }^{\circ} \mathrm{C}$ [29]. This drop, however, was attributed to the formation of $\mathrm{Fe}_{2} \mathrm{C}$ carbides in the martensite laths. Additionally, a further increase in tempering temperature led to the dissolution of the $\mathrm{Fe}_{2} \mathrm{C}$ phase and the toughness recovered back to $40 \mathrm{~J}$.

Mirzaee et al. observed that, for 410 and $410 \mathrm{Ni}$ steel, the ideal balance between toughness and hardness was observed when tempered at $450{ }^{\circ} \mathrm{C}$ and $550{ }^{\circ} \mathrm{C}$. They attributed this to secondary hardening that resulted from primary and secondary carbide precipitation [30]. The toughness for both $450{ }^{\circ} \mathrm{C}$ and $550{ }^{\circ} \mathrm{C}$ tempered materials at a $-18{ }^{\circ} \mathrm{C}$ test temperature were approximately $42 \mathrm{~J}$ and $38 \mathrm{~J}$, respectively. Bilmes et al. also noted excellent toughness due to $600{ }^{\circ} \mathrm{C}$ PWHT of $13 \mathrm{Cr}-\mathrm{NiMo}$ martensitic steel [31]. For the as-welded material, using single-stage tempering increased the toughness at the $20{ }^{\circ} \mathrm{C}$ test condition from $73 \mathrm{~J}$ to $116 \mathrm{~J}$. While the majority of the work has focused on the tempering studies of welds, there are studies where austenitizing and tempering have been explored as well [30].

The above review of the literature clearly shows the efficacy of post-processing to effectively "reset" the microstructure and eliminate $\delta$-ferrite. Although the extant literature provides a background towards understanding the science of processing 410 via additive manufacturing, there are significant gaps that need to be addressed:

1. The rapid cooling rates and complex thermal gyrations can lead to formation of non-equilibrium phases after solidification and from solid-solid phase transformation, as described previously. A detailed study on these complex phase transformations in 410 steel does not exist.

2. The role of such heterogeneity in microstructure on the mechanical properties is not well established.

3. As pointed out in the previous paragraph, there is no consensus in the additive manufacturing field on the PWHT treatments used to achieve a balance in properties of martensitic stainless-steel weld metal.

This study aims to address these gaps by performing systematic characterization of 410 SS samples that are fabricated using arc-based additive manufacturing. The associated scatter in mechanical properties was correlated to the microstructure, particularly the fraction of $\delta$-ferrite. Following this, the effect of various heat treatment cycles-(i) austenitizing and (ii) austenitizing and tempering-to reset the microstructure and reduce the scatter in properties were evaluated. The results strongly suggest that the $\delta$-ferrite can be linked to the reduction in toughness and the existence of local soft spots in the as-printed microstructure. A post-austenitizing heat treatment on the builds simply reset the microstructure by eliminating $\delta$-ferrite, which led to a significant reduction in the scatter of tensile properties while simultaneously improving the impact toughness.

\section{Materials and Methods}

\subsection{Control Strategy and Process Conditions During Sample Fabrication Process}

All builds were manufactured using a Lincoln Electric wire-arc additive cell that consists of a six-degrees-of-freedom (DOF) ABB IRB-2600 robot with a Lincoln Electric PowerWave R500 power source. The wire used was a Lincoln Electric Blue Max MIG 410 (ER410) (Lincoln Electric Inc., Cleveland, $\mathrm{OH}, \mathrm{USA}$ ) with a 0.045 -inch diameter. Sample fabrication included two vertical wall designs: one for tensile test specimens and the other for Charpy impact test specimens, based on ASTM standards E8/E8M and ASTM E23-09, respectively [32,33]. The dimensions for the Charpy test specimen wall were $362 \mathrm{~mm}(\mathrm{~L}) \times 305 \mathrm{~mm}(\mathrm{~T}) \times 12.8 \mathrm{~mm}(\mathrm{~W})$, and the dimensions for the tensile test specimen wall were $600 \mathrm{~mm}(\mathrm{~L}) \times 327 \mathrm{~mm}(\mathrm{~T}) \times 12.8 \mathrm{~mm}(\mathrm{~W})$. The wall for tensile samples was cut in half; one half was used in the "as-printed" state and the other half was subjected to heat treatment. All builds were constructed on one-inch-thick low-carbon steel build plates (ASTM A108). Each layer of deposited material was approximately $3.2 \mathrm{~mm}$ high and the total number of layers was 95 layers and 102 layers 
for the Charpy and tensile walls, respectively. Center-to-center bead spacing was $3.2 \mathrm{~mm}$, such that each layer was built using a continuous print pattern measuring four beads in width. The welding parameters used for all builds utilized Lincoln Power Mode ${ }^{\mathrm{TM}}$ (Lincoln Electric Inc., Cleveland, OH, USA) with the following input settings: $2.5 \mathrm{~kW}$ welder power, a travel speed of $406 \mathrm{~mm} / \mathrm{min}$, and a wire feed speed of $5.6 \mathrm{~m} / \mathrm{min}$. Power Mode ${ }^{\mathrm{TM}}$ attempts to maintain a constant power input; therefore, the typical realized current and voltage values were around $15.5 \mathrm{~V}$ and $160 \mathrm{~A}$. The shield gas was trimix $\left(90 \% \mathrm{He} / 7.5 \% \mathrm{Ar} / 2.5 \% \mathrm{CO}_{2}\right)$.

\subsection{Heat Treatment Schemes for Sample Fabrication}

As mentioned in the previous section, two heat treatment cycles were used to develop post-processing protocols: austenitization heat treatment and tempering. Austenitization heat treatment was performed at $1050{ }^{\circ} \mathrm{C}$ for $60 \mathrm{~min}$ followed by air cooling. The austenitization temperature was determined based on the published literature which showed significant increase of average grain size above austenitization temperature of $1050{ }^{\circ} \mathrm{C}$ [34]. The heat treatments were done in an inert atmosphere to avoid any oxidation on the samples. After austenitization, one section of the block was retained to investigate the mechanical properties in the as-austenitized condition while the other sections were tempered. After austenitizing, the samples were tempered at $350{ }^{\circ} \mathrm{C}, 450{ }^{\circ} \mathrm{C}, 550{ }^{\circ} \mathrm{C}$, $650^{\circ} \mathrm{C}$, and $750^{\circ} \mathrm{C}$ for $90 \mathrm{~min}$ each, followed by air cooling. Tempering was also performed in an inert atmosphere. The heating rate used was $10{ }^{\circ} \mathrm{C} / \mathrm{min}$ and thermocouples attached to the printed blocks were used to monitor the temperature during heat treatment. This approach yielded three different conditions: as printed, austenitized, and tempered samples.

\subsection{Mechanical Testing}

Printed and heat-treated walls were machined for a set of samples for systematically preplanned tests, i.e., tensile tests, Charpy V-notch toughness test, hardness, and metallography. Figure 1 shows the layout drawing for sample locations within the builds for (a) Charpy toughness and (b) uniaxial tensile tests.

For Charpy V-notch tests, standard size samples (according to ASTM E23-09) with $55 \mathrm{~mm}$ long and $10 \mathrm{~mm} \times 10 \mathrm{~mm}$ cross-section were machined from the fabricated wall. The samples were machined from two orientations, i.e., along the axis parallel to build direction $Z$ and perpendicular to build direction $Y$. The $Y$-labeled samples had the notch along the $Z$ (build) direction and vice versa. Three sets of samples parallel to the build direction $Z$ were prepared at different heights of the wall, and four sets of samples perpendicular to the build direction $Y$ were machined for toughness testing. In total, 20 Y-labeled and 30 Z-labeled Charpy samples were prepared (refer Figure 1a) to capture detailed toughness characteristics of the samples as a function of location and orientation against build direction. The tests were conducted on a Tinius Olsen Charpy Impact Machine (Tinius Olsen TMC, Horsham, PA, USA) with $407 \mathrm{~J}$ capacity at $0{ }^{\circ} \mathrm{C}$ to $200{ }^{\circ} \mathrm{C}$ test temperature with a step interval of $50{ }^{\circ} \mathrm{C}$.

For the tensile test, sub-sized specimens based on ASTM E8/E8M were prepared. The specimens had overall length of $100 \mathrm{~mm}$ with gauge length and width $25 \mathrm{~mm}$ and $6 \mathrm{~mm}$, respectively. The width of the grip section was $10 \mathrm{~mm}$. In total, 33 samples were cut from three different orientations (refer Figure 1 b), i.e., parallel, $45^{\circ}$, and perpendicular to the build direction. Specimens in those three orientations were machined at different heights from $5 \mathrm{~mm}$ above bottom zone of the built wall to $5 \mathrm{~mm}$ below the top surface. The tensile tests were carried out on a $100 \mathrm{kN}$ capacity MTS SHM-07, four-pillar tensile frame at room temperature using a strain rate of $0.076 \mathrm{~s}^{-1}$. The yield strength was measured using a $0.2 \%$ offset method applied on tensile test data. 


\section{(a)}
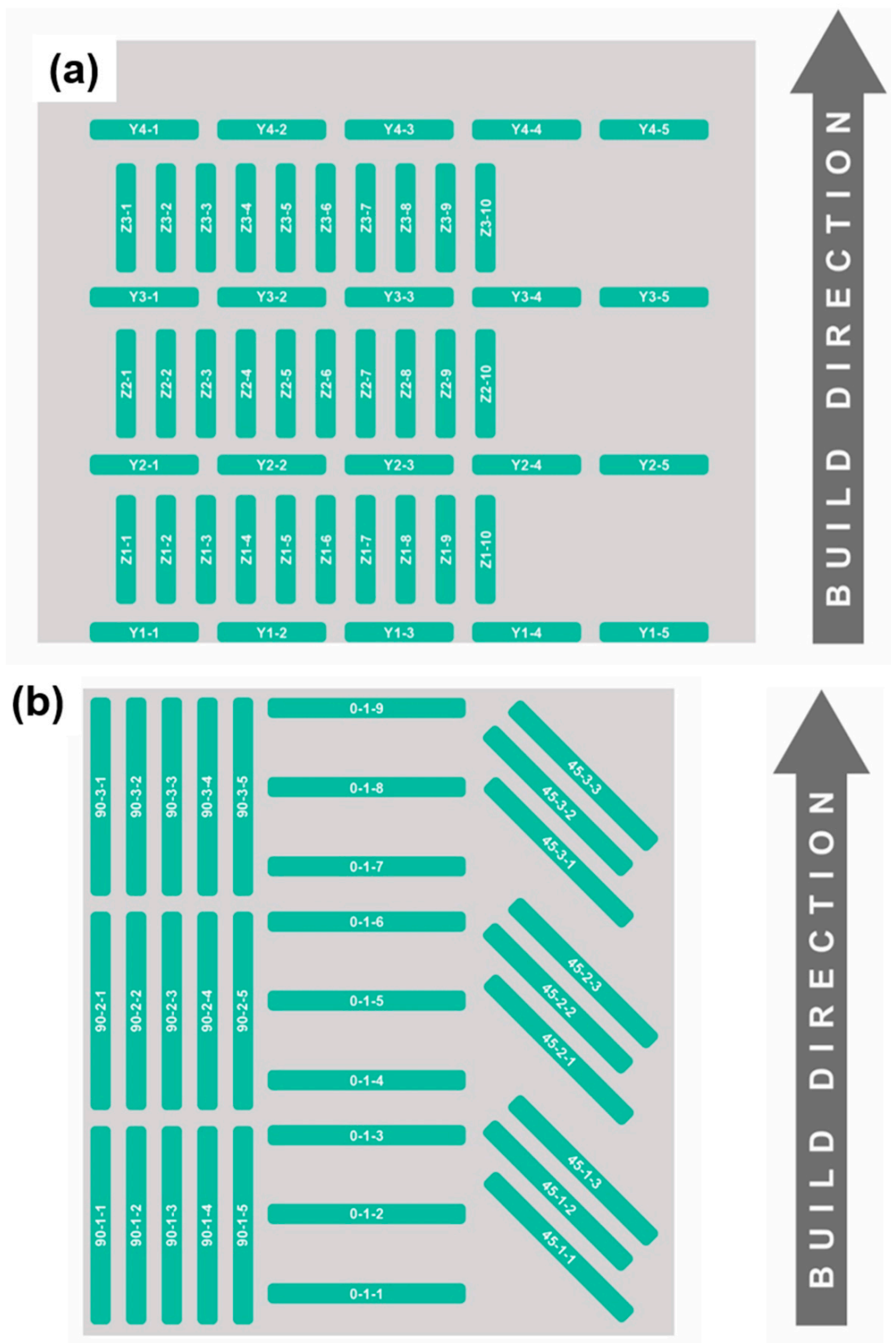

Figure 1. Pictorial representation of the (a) Charpy V-notch samples ( $305 \mathrm{~mm}$ tall $\times 362 \mathrm{~mm}$ long wall) and (b) tensile test samples ( $327 \mathrm{~mm}$ tall $\times 300 \mathrm{~mm}$ long wall-representative of the as-printed half).

\subsection{Microstructural Characterization}

Samples for microstructural observation were machined from the center of build, $50 \mathrm{~mm}$ from the top, and $50 \mathrm{~mm}$ from the substrate region along the build direction and across wall thickness. The samples were mounted in conductive epoxy and later prepared using conventional metallographic procedures with $1 \mu \mathrm{m}$ diamond paste finish. Two-dimensional hardness distribution measurement was conducted using a Leco LM100AT micro hardness tester (LECO Corporation, St. Joseph, MI, USA) using a $300 \mathrm{~g}$ load. Approximately $8 \mathrm{~mm} \times 10 \mathrm{~mm}$ cross-sectional samples were sectioned from the $X-Z$ plane of fabricated walls and hardness values were captured from above 2200 locations to formulate the hardness maps. The samples were then etched using with an etchant consisting of $80 \% \mathrm{H}_{2} \mathrm{O}, 15 \% \mathrm{HCl}$, and $5 \% \mathrm{HNO}_{3}$. Optical microscopy was performed using a Leica DMi8C optical microscope (Leica Microsystems Inc., Buffalo Grove, IL, USA). Scanning electron microscopy was performed using a JEOL 6500 FEG SEM (Tokyo, Japan) at an accelerating voltage of $20 \mathrm{kV}$ with a probe current of $4 \mathrm{nA}$. Electron back scatter diffraction was also acquired on the same equipment using an 
accelerating voltage of $20 \mathrm{kV}$ and a probe current of $4 \mathrm{nA}$ with a step size of $1 \mu \mathrm{m}$. The analysis was performed on the EDAX TSL OIM analysis software v8.

\section{Results Discussions}

\subsection{Characterization of the As-Printed Samples-Mechanical Testing}

\subsubsection{Tensile Testing}

Proper verification of the build material strength is required before deployment of AM technology into the field. Figure $2 \mathrm{a}-\mathrm{c}$ shows the tensile test data from nine representative as-printed samples, taken from the $0^{\circ}, 45^{\circ}$, and $90^{\circ}$ orientations. Specifically, in the samples extracted perpendicular to the build the direction, it was observed that the sample (sample $0-1$ ) with lowest strength and highest ductility was extracted at locations close to the substrate (low-C steel). The dilution with low-C steel (base plate) resulted in a higher elongation and lower strength. For the as-printed samples, the average yield stress was $784 \pm 84 \mathrm{MPa}$ and the ultimate tensile stress was $1135 \pm 97 \mathrm{MPa}$. The standard deviations of both yield stress and ultimate tensile stress were significantly high, which indicates extensive scatter in the tensile test data. The average fracture strain for the $0^{\circ}$-orientation samples was higher compared to the samples from the other two orientations. The standard deviation of the fracture strain values was high in all three directions. Average fracture strain for all as-printed samples was $6.5 \pm 3 \%$. The primary source of scatter can be attributed to alternating bands of tempered and untempered martensite, which form during continuous thermal cycling in the printed wall.

(a)

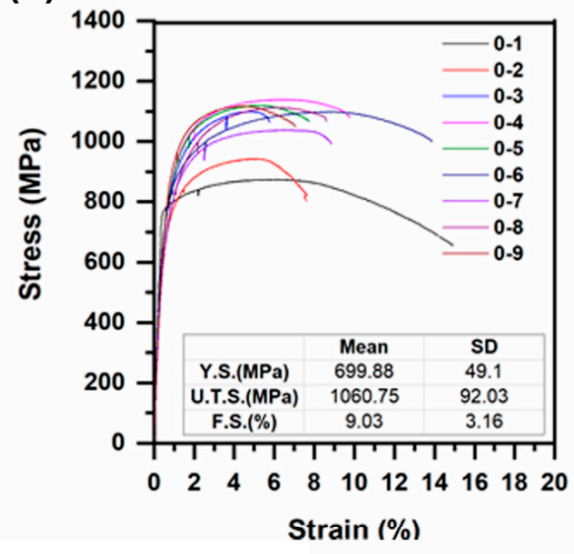

(b)

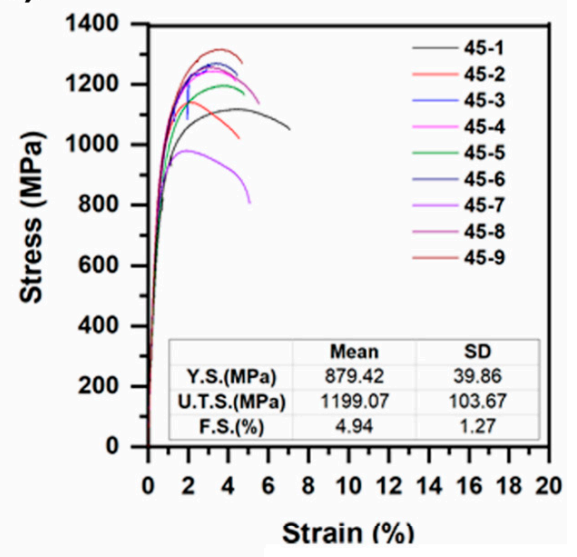

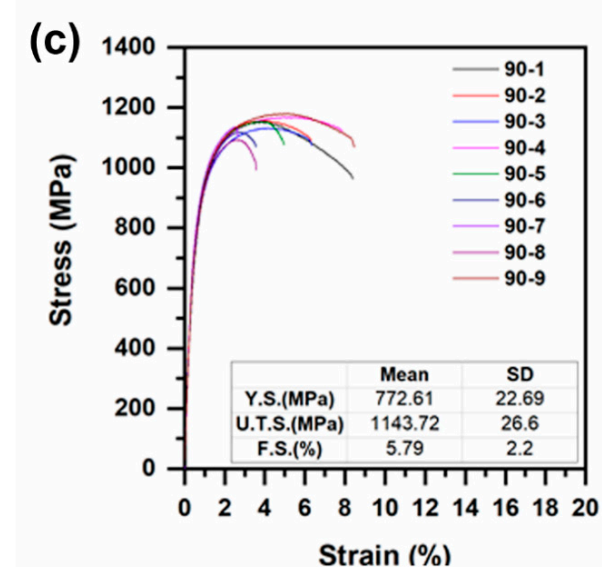

Figure 2. Stress versus strain curves: (a) perpendicular; (b) $45^{\circ}$; and (c) parallel to build direction, in as-printed samples. (Here, Y.S., U.T.S., and F.S. denote yield strength, ultimate tensile strength, and fracture strain, respectively.) 


\subsubsection{CVN Toughness Testing}

The results from the Charpy tests are shown in Figure 3, which also represents the anisotropy feature of the as-printed samples. The samples taken parallel to the build direction are labeled as $Z$ samples and the samples taken perpendicular to the build direction are referred to as $Y$ samples (Figure 1). Figure 3 shows the Charpy test data from 50 different samples machined from two different orientations and tested between $0{ }^{\circ} \mathrm{C}$ and $200^{\circ} \mathrm{C}$.

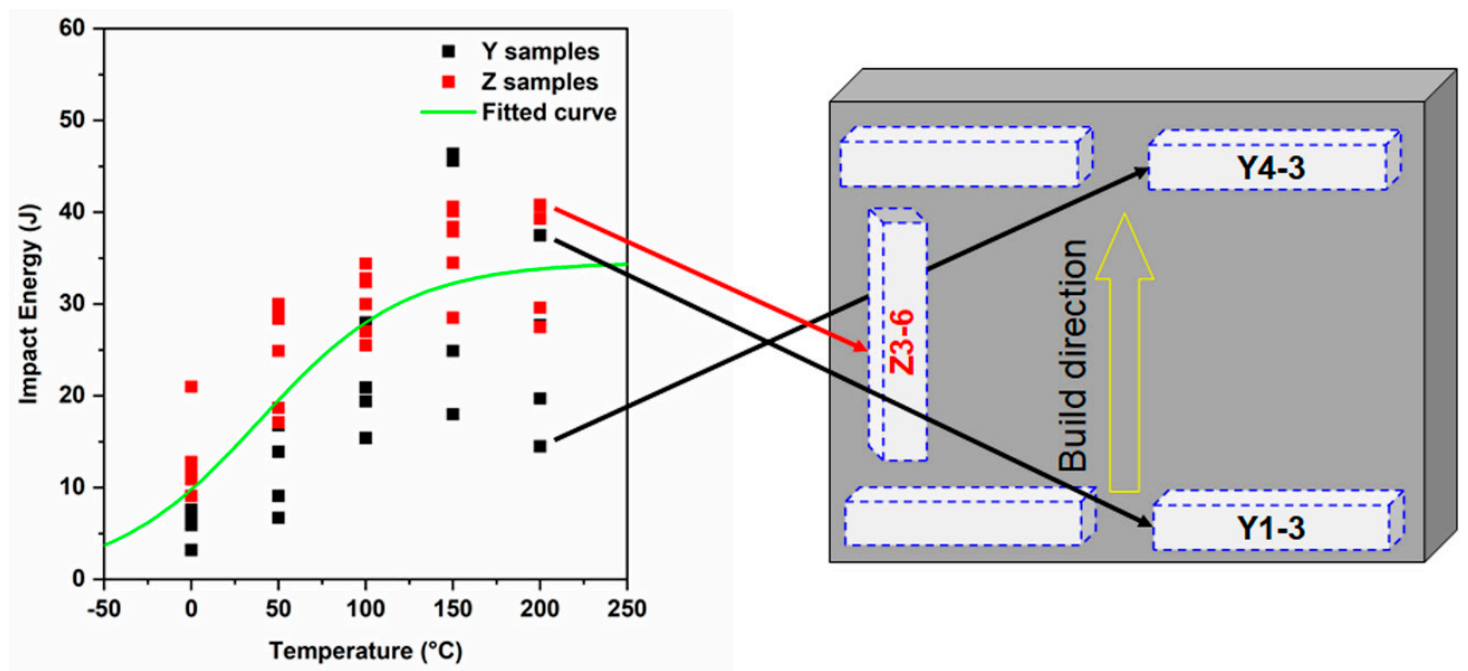

Figure 3. Charpy impact toughness results of perpendicular $(Y)$ and parallel $(Z)$ to build direction.

To measure the DBTT, the toughness values were fitted using a nonlinear regression curve fit based on the

$$
\text { Impact Toughness }=+\mathrm{B}_{0} \tanh \left(\frac{\mathrm{T}-\mathrm{T}_{0}}{\mathrm{C}_{0}}\right)
$$

where $\mathrm{A}_{0}, \mathrm{~B}_{0}, \mathrm{C}_{0}$, and $\mathrm{T}_{0}$ are constants and $\mathrm{T}$ is the temperature. The DBTT is defined as the temperature corresponding to half the height of the transition curve. The ductile-to-brittle transition temperature, determined using this approach, was $\sim 70{ }^{\circ} \mathrm{C}$. The upper shelf energy was approximately $35 \mathrm{~J}$ and lower shelf energy was below $5 \mathrm{~J}$. Overall, the samples extracted along the $Y$ direction showed lower toughness (for example, at $\sim 75 \mathrm{~mm}$ above base plate, the toughness of the $Y$ sample was around $7 \mathrm{~J}$, but for the $Z$ sample, the toughness was approximately $17 \mathrm{~J}$ at $0{ }^{\circ} \mathrm{C}$ ) compared to samples extracted along the $Z$-axis, indicating directionality in the printed samples. While the samples extracted along the $Z$-axis consistently showed higher toughness values than the samples from the $Y$ direction, there was also a significant scatter within the data. For example, the sample Y1-3 tested at $200{ }^{\circ} \mathrm{C}$ showed a toughness of $37 \mathrm{~J}$ while another sample $\mathrm{Y} 4-3$ showed a toughness of $14 \mathrm{~J}$, indicating that in addition to the direction, the toughness is also a function of the notch microstructure. Note that the scatter band also starts to widen at higher temperatures, showing a heterogeneity in the microstructure. In addition, samples obtained from the bottom region of the build exhibited higher toughness values than those from the top. This trend occurred at all temperatures, especially in samples extracted along the $Y$ direction where this was most pronounced.

Fractography was performed to investigate the differences in surface morphology among the various samples and the results are summarized in Figure 4. Figure 4a shows the pictorial diagram of analyzed Charpy samples on the fabricated wall. The fractography of samples extracted from the bottom-most region of the build (where the build meets the base plate) showed no brittle failure (Figure $4 \mathrm{~d}, \mathrm{e}$ ), but samples extracted at $275 \mathrm{~mm}$ away from the base plate displayed brittle failure (Figure $4 \mathrm{~b}$,c showing cleavage fracture with a flat surface as pointed by yellow arrows). The point count method was used to estimate the fraction of brittle failure zones in the images, which ranged 
from $1.96 \%$ to $18.9 \%$. The fractography also corroborates the toughness data because the samples extracted from the top of the plate (Y4 samples) had a higher fraction of brittle failure.

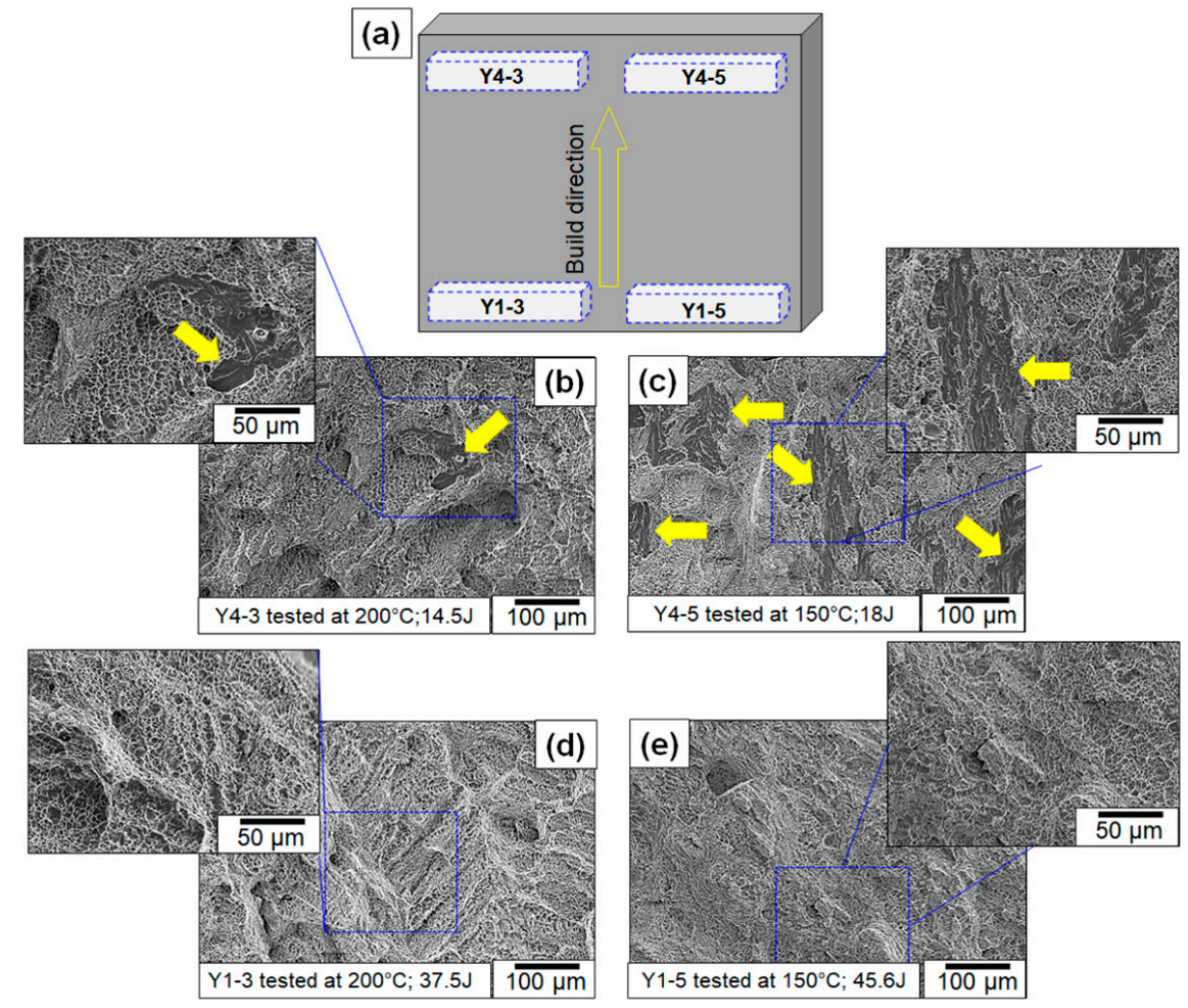

Figure 4. (a) Pictorial diagram showing the position of Charpy samples on the fabricated wall. Fractographs of Charpy samples sectioned from $(\mathbf{b}, \mathbf{c})$ top and $(\mathbf{d}, \mathbf{e})$ bottom of the build. Yellow arrows are showing brittle failure modes in the above figures.

In addition, the failure morphology also suggested that the regions where shear propagation occurred could also correspond to the locations where $\delta$-ferrite existed. Figure 5 illustrates optical micrographs showing the representative microstructure taken from different locations in as-printed wall. The areas with a bright contrast and non-characteristic relief correspond to $\delta$ ferrite. The area fraction of $\delta$ ferrite was measured at each location using the micrographs and some representative images are showed below. The results indicated that the top portion exhibited a greater amount of $\delta$ phase than the other locations. This suggests that for $Y$-labeled samples especially, the top region had comparatively higher $\delta$-ferrite contributing to the lower toughness values. Therefore, hardness testing at various locations in the builds and optical microscopy were performed.

\subsubsection{Hardness Mapping}

Hardness mapping was used to investigate the local heterogeneity of the microstructure and rationalize the toughness behavior. The hardness maps were performed on the top, middle, and bottom regions of the builds. Figure 6 shows the hardness maps from the (a) top, (b) middle, and (c) bottom regions of the as-printed samples. The contour maps clearly show that there are significant soft spots in the samples. The soft spots appeared sporadically and did not form a pattern. These soft spots can be attributed to formation of $\delta$-ferrite during the wire arc additive manufacturing process. The hardness distribution histogram of each region was plotted and fitted using a Gaussian distribution (Figure 6d). The data shows a higher standard deviation in the sample from the top section of the build ( $38 \mathrm{HVN}$ compared to $22 \mathrm{HVN}$ in the middle and bottom), indicating a higher probability of scatter in the samples from those locations. Higher thermal cycling leads to homogenization of the microstructure and, therefore, the samples from the bottom should have a slightly lower scatter in properties. 

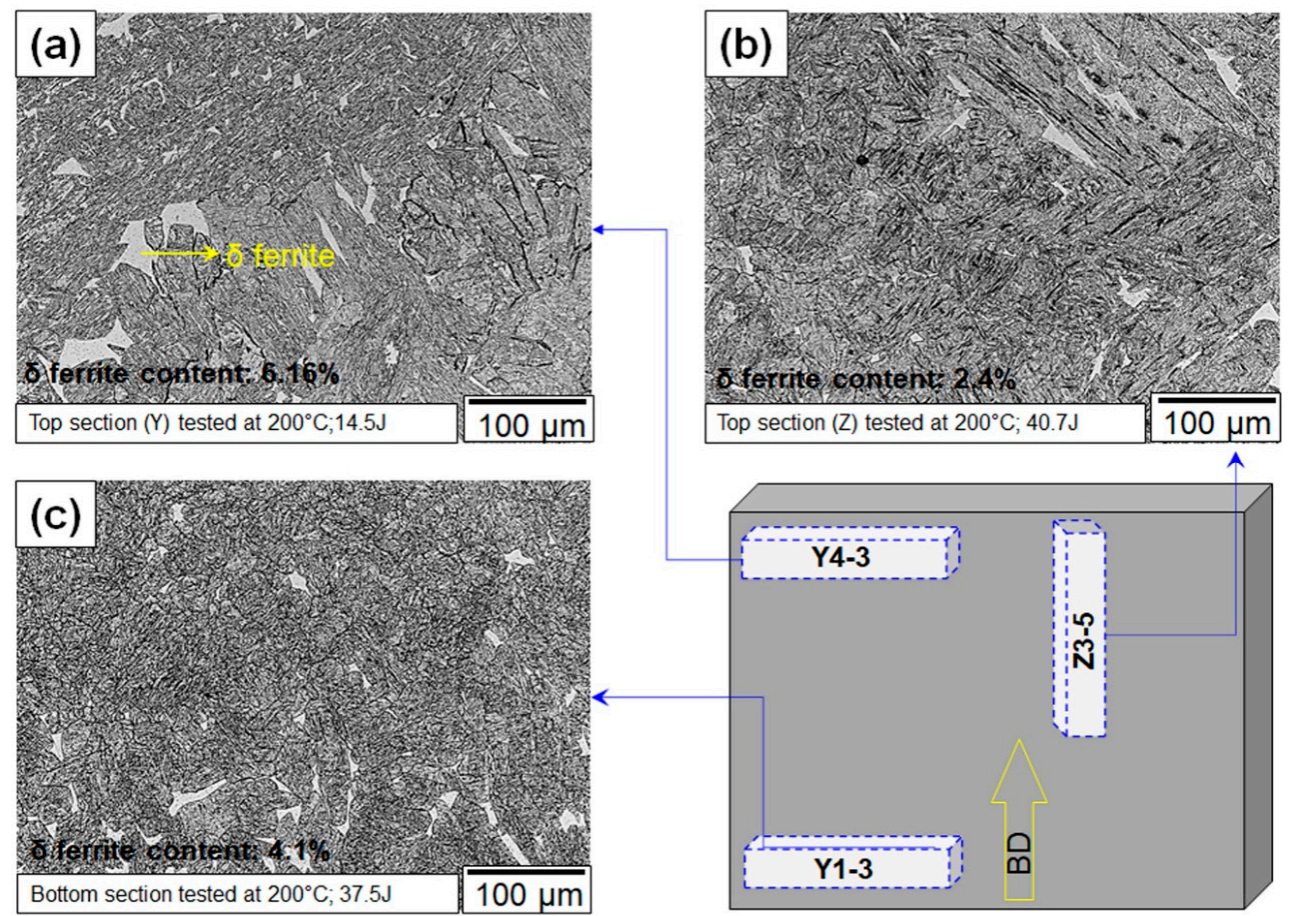

Figure 5. Representative microstructural observation on failed Charpy samples sectioned (a,c) perpendicular and (b) parallel to build direction from different build heights.

(a)

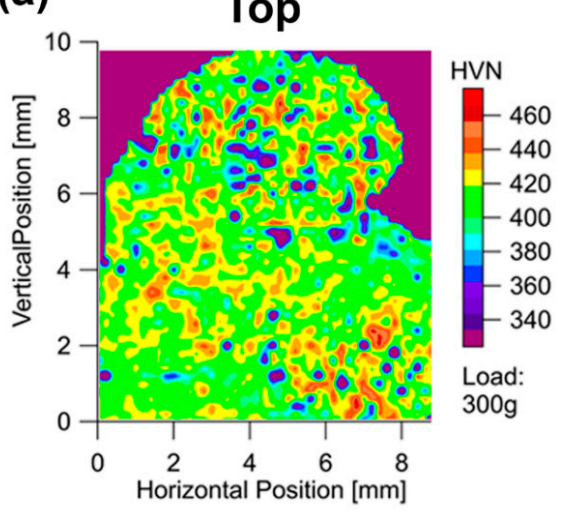

(c)

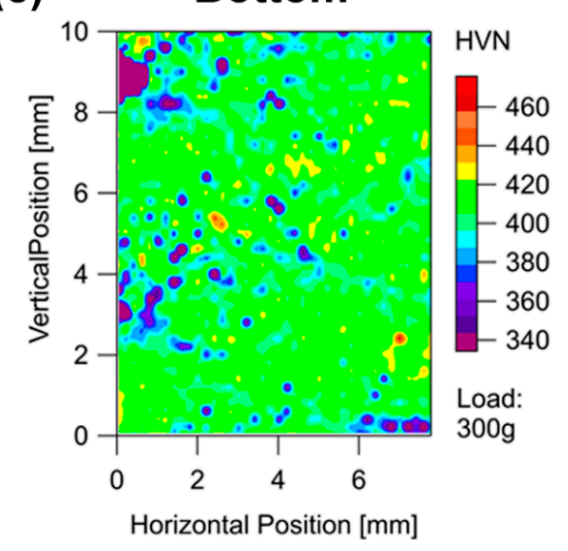

(b)

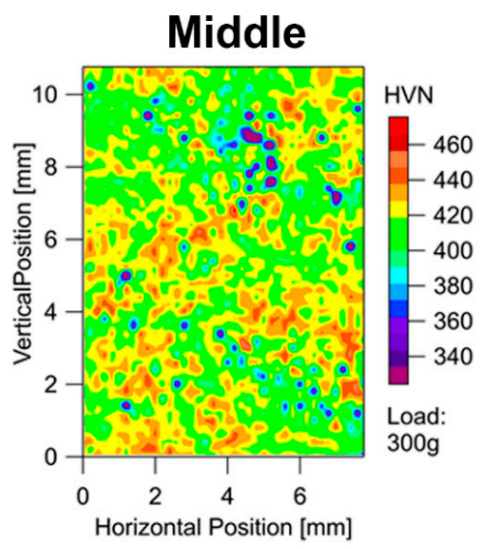

(d)

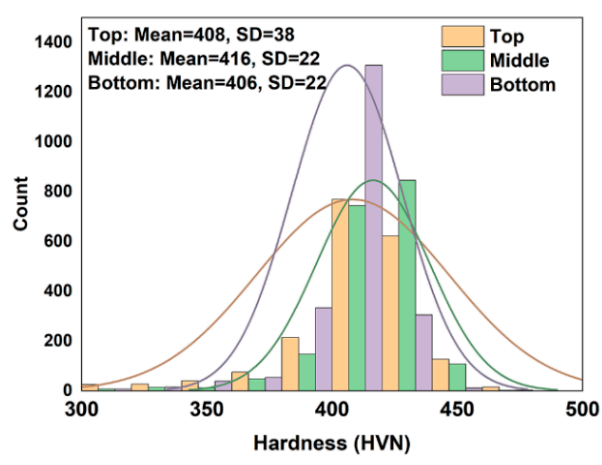

Figure 6. Hardness maps from different locations in the build height: (a) top; (b) middle; (c) bottom of the build. (d) Hardness distribution histogram of each region. 


\subsubsection{Microstructure Characterization}

To confirm the results from the hardness tests and also rationalize the large scatter in toughness, a detailed characterization campaign was initiated. Figure 7 shows the electron backscatter diffraction (EBSD) micrographs of the samples from various locations of the builds. The data show that the bottom regions are predominantly martensitic with limited $\delta$-ferrite stringers. The $\delta$-ferrite stringers present are along the inter-dendritic regions with similar orientations, which suggests that the $\delta$-ferrite formed during solidification and not during the thermal cycling. The progressive increase in the $\delta$-ferrite in the samples extracted from the upper region of the build, which undergoes fewer thermal cycles, supports this interpretation. The morphology of the $\delta$-ferrite changes from stringers to blocky $\delta$-ferrite.
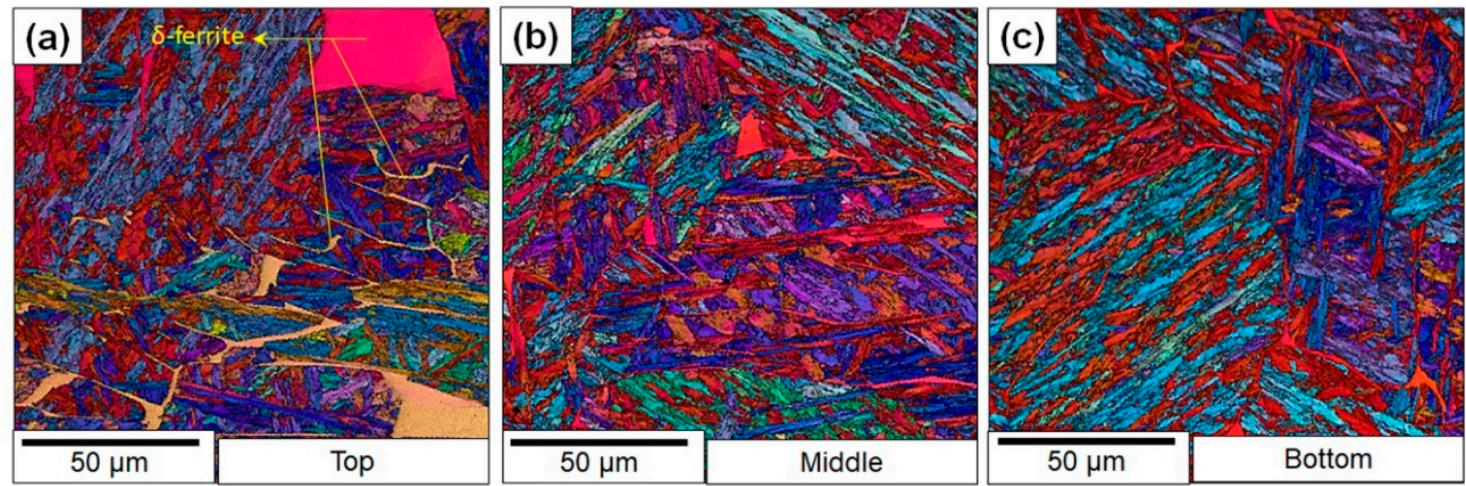

Figure 7. Electron backscatter diffraction (EBSD) micrographs of as-printed samples sectioned from different locations on the wall: (a) top; (b) middle; (c) bottom.

It is possible that inclusions contributed to brittle failure by serving as crack nucleation points. This hypothesis was ruled out in the present case because the fractography analysis did not show any evidence of cracks nucleating from the inclusions. Therefore, to rationalize the cause for the toughness scatter, the notch microstructures of samples were studied. The corresponding microstructures are presented. The microstructure shows that the difference in $\delta$-ferrite fractions between the $Y$ and $Z$ samples. The average percentage of the area that was covered by $\delta$-ferrite in the $Y$ samples was $5 \% \pm 1 \%$, whereas for Z-labeled samples, it was $3 \% \pm 1 \%$. In addition, the optical micrographs (Figure 8 ) also showed a more refined prior austenite grain size in the bottom regions of the builds compared to the top regions, where coarse columnar grains were observed (Figure 8a). Both the reduced $\delta$-ferrite content and the refinement of the prior austenite grains could have also contributed to the increased toughness in the bottom locations of the build.
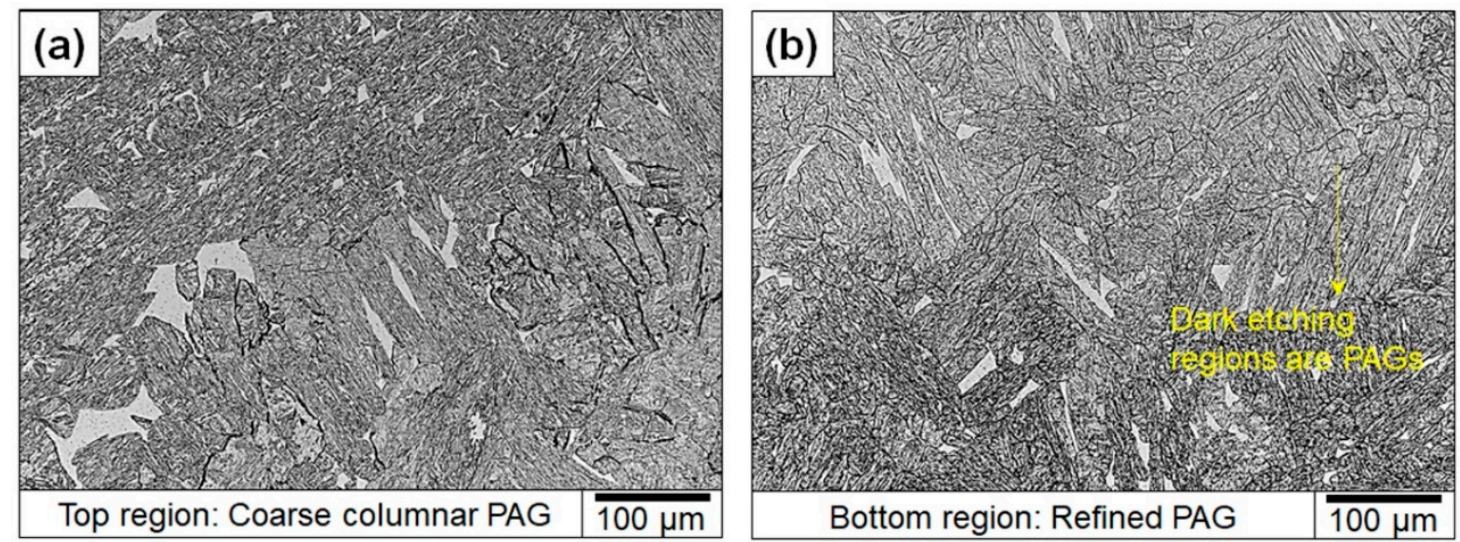

Figure 8. Optical micrograph showing differences in grain microstructure at (a) top and (b) bottom of the builds in as-printed condition. 
Based on the characterization and property evaluation above, two important events can be hypothetically highlighted in the microstructure evolution at the bottom region, as listed below:

1. Elimination of $\delta$-ferrite during thermal cycling: The bottom locations undergo significantly more thermal cycling. As pointed out previously, there are five distinct zones in the reheated heat-affected zones [22]. Of the five zones, repeated thermal cycling in the fully austenitic zone would lead to the gradual dissolution of the $\delta$-ferrite pockets [18]. Upon cooling, the reheated zone transforms from the fully austenitic region to martensite without any $\delta$-ferrite, depending on heating and cooling rates. This results in the gradual decrease in $\delta$-ferrite during every cycle in which the temperature is in the fully austenite region. This repeated reheating and cooling in the bottom regions of the build could have contributed to the reduction in $\delta$-ferrite as shown in the micrographs and in the hardness results.

2. Grain refinement: During the reheating cycles, the material is reheated to the inter-critical temperature in which new austenite reversion occurs. The reverted austenite recrystallizes, leading to the refinement of the prior austenite grains [35]. The recrystallization of the austenite is driven by the high stored energy form dislocations which form via shear mechanism during the retransformation to austenite. Dislocation densities exceeding $10^{11} / \mathrm{cm}^{3}$ have been documented in reverted austenite [36]. This only occurs when the heating rate is beyond a critical value, typically $\sim 100{ }^{\circ} \mathrm{C} / \mathrm{s}$. Upon cooling, these refined austenite grains transform to martensite with an improved toughness, due to a reduction in the prior austenite grain size. When the heating rates are much higher and close to $1000^{\circ} \mathrm{C} / \mathrm{s}$, the refinement is dramatic due to a different mechanism. In this case, the refinement is dominated by a packet refinement mechanism, as opposed to prior austenite grain refinement. When the alloy is rapidly heated at the mentioned heating rates to accomplish austenite reversion, the reversion occurs without any recrystallization. The high dislocation density leads to more heterogeneous nucleation of martensite with a higher defect density. Due to this heterogeneous nucleation, martensite formation is suppressed via bivariant blocks or packets, and all of the 24 different variants appear randomly [35]. Thermal cycling therefore breaks down the columnar austenite grains that form during solidification by either recrystallization or packet refinement. The exact mechanism by which the refinement occurs is still unclear, and more work is necessary to develop a fundamental understanding of the microstructure evolution.

\subsection{Experimental Results on the Heat-Treated Samples}

Based on the characterization results of as-built material and the literature, the low toughness was attributed to presence of $\delta$-ferrite. Therefore, heat treatments were designed to eliminate the $\delta$-ferrite. To that effect, two different types of heat treatments were performed: (a) austenitization at $1050^{\circ} \mathrm{C}$ for $60 \mathrm{~min}$ followed by water quenching and (b) austenitization and tempering at $350{ }^{\circ} \mathrm{C}, 450{ }^{\circ} \mathrm{C}, 550{ }^{\circ} \mathrm{C}$, $650^{\circ} \mathrm{C}$, and $750^{\circ} \mathrm{C}$ temperatures for $90 \mathrm{~min}$ each. The aim of the austenitization treatment was to understand if the low toughness was purely a function of the high $\delta$-ferrite content in the builds or if it was also due to the presence of untempered martensite. Therefore, the austenitization heat treatment was designed to eliminate the $\delta$-ferrite while having a homogenous untampered martensite.

\subsubsection{Tensile Testing on Austenitized Samples}

The results of tensile tests the on representative 27 samples sectioned in three different directions are presented in Figure $9 \mathrm{a}-\mathrm{c}$. The scatter of tensile properties disappeared after austenitization. Three austenitized samples (with $0^{\circ}$ orientation) showed fracture with a very low strain percentage which may have been due to the presence of discontinuities in microstructure. The yield and ultimate stress levels were comparable in all three directions for the samples, showing there was no directionality in tensile stress behavior. Figure $9 \mathrm{~d}$ shows an overall effect due to austenitization as compared to as-printed samples. The standard deviation among both yield (24 MPa) and ultimate (17 MPa) tensile strength was significantly lower compared to the as-printed cases. In particular, the standard deviation for yield strength reduced $84 \mathrm{MPa}$ on as-printed samples to $24 \mathrm{MPa}$ as depicted above; a $70 \%$ reduction 
in the scatter on tensile strength was possible due to austenitization treatment. Austenitizing helped to enhance the yield stress from $784 \mathrm{MPa}$ to $942 \mathrm{MPa}$ and ultimate tensile stress from 1135 to $1226 \mathrm{MPa}$. Excluding three $0^{\circ}$-orientation samples with very low fracture strains, the average fracture strain of the remaining austenitized samples was $11 \% \pm 1 \%$. This confirms an increase the in average fracture strain value with decreased scatter in the number of individual fracture strains. The drastic reduction in scatter after austenitizing treatments suggests that the scatter in the as-built material was mostly associated with microstructural heterogeneity, together with the dispersion of $\delta$ ferrite.

(a)
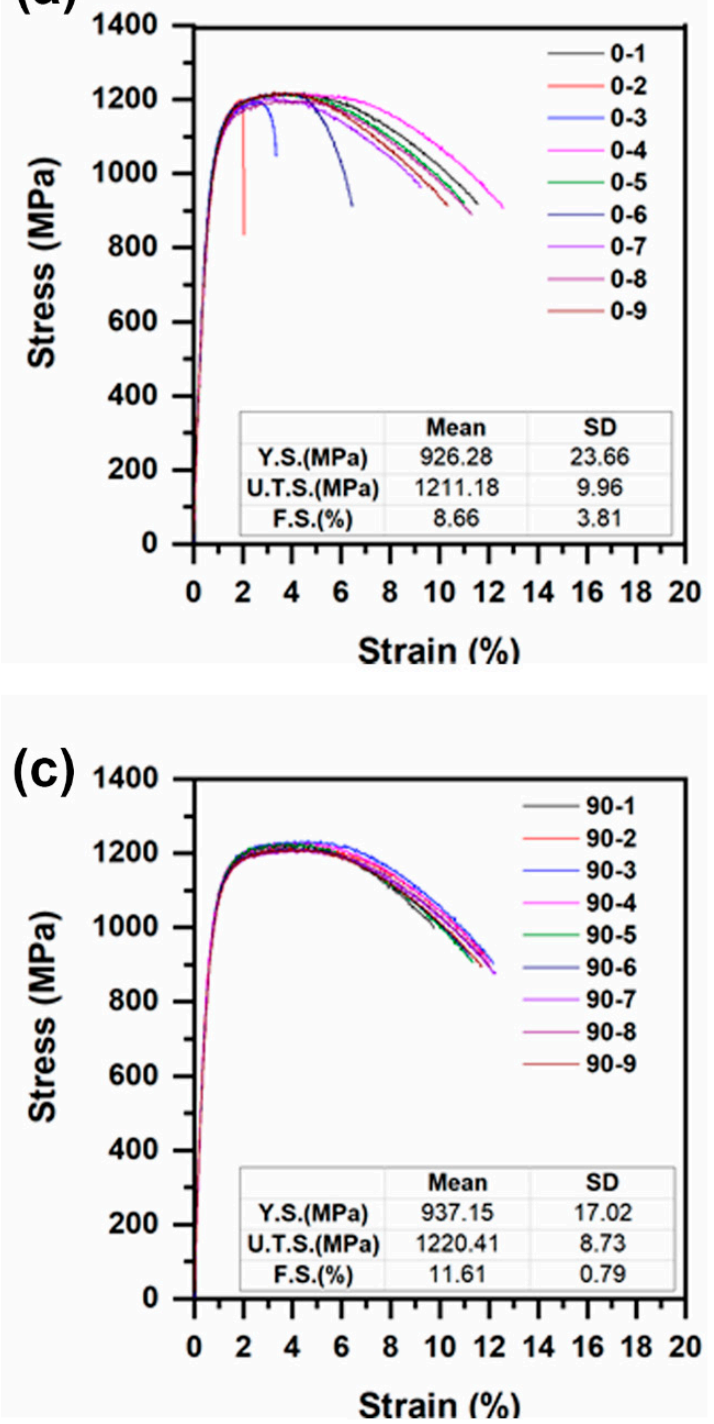

(b)

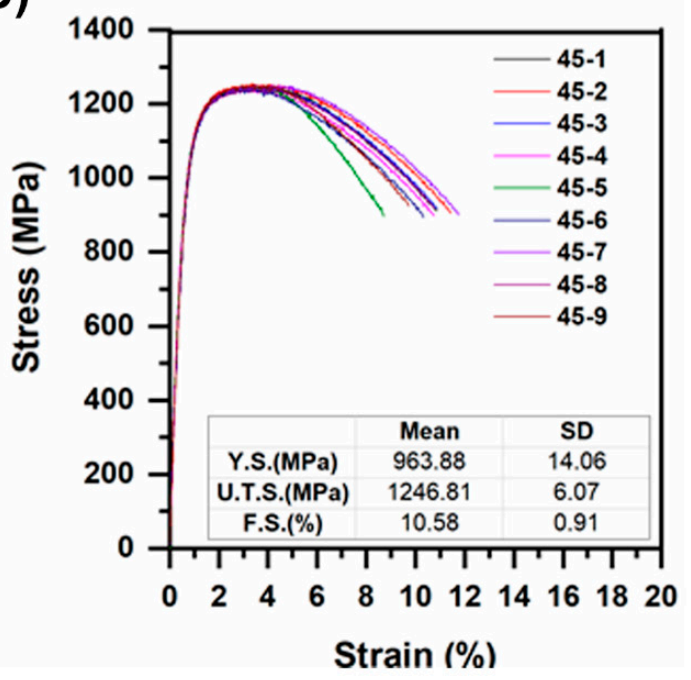

(d)

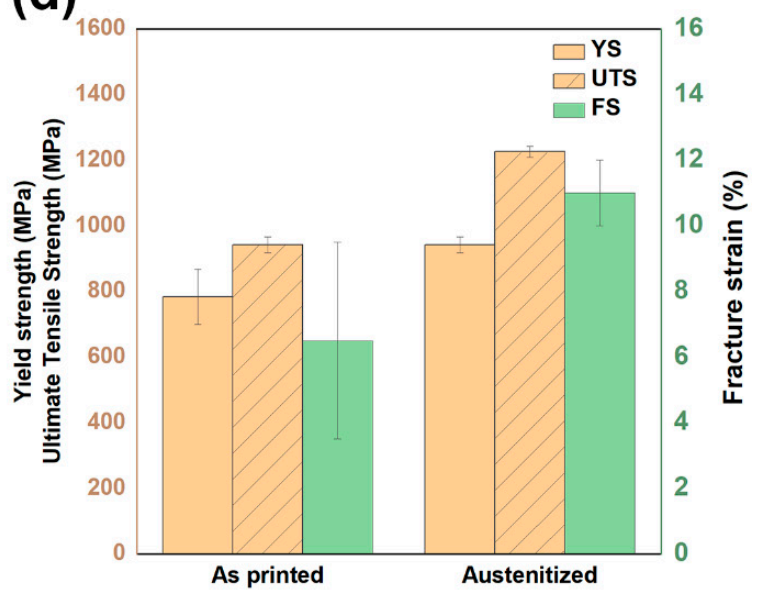

Figure 9. Stress versus strain curves (a) perpendicular; (b) $45^{\circ}$; (c) parallel to build direction for austenitized samples. (d) Comparative bar graph of yield stress, ultimate tensile stress, and fracture strain data in as-printed and austenitized samples. (Here, Y.S., U.T.S. and F.S. denote yield strength, ultimate tensile strength, and fracture strain, respectively.)

\subsubsection{CVN Toughness and Hardness Mapping on Testing on Austenitized Samples}

Figure 10a shows the Charpy test data from the austenitized samples. The average impact energy, even at $0{ }^{\circ} \mathrm{C}$, was $27 \mathrm{~J}$ with a standard deviation of $2 \mathrm{~J}$, in contrast to the average toughness of the as-printed samples at $50{ }^{\circ} \mathrm{C}$, which was $22 \mathrm{~J}$ with a standard deviation of $8 \mathrm{~J}$. The results clearly 
demonstrate the beneficial effect of eliminating $\delta$-ferrite in the samples. The scatter and anisotropy in the samples were also significantly lower.
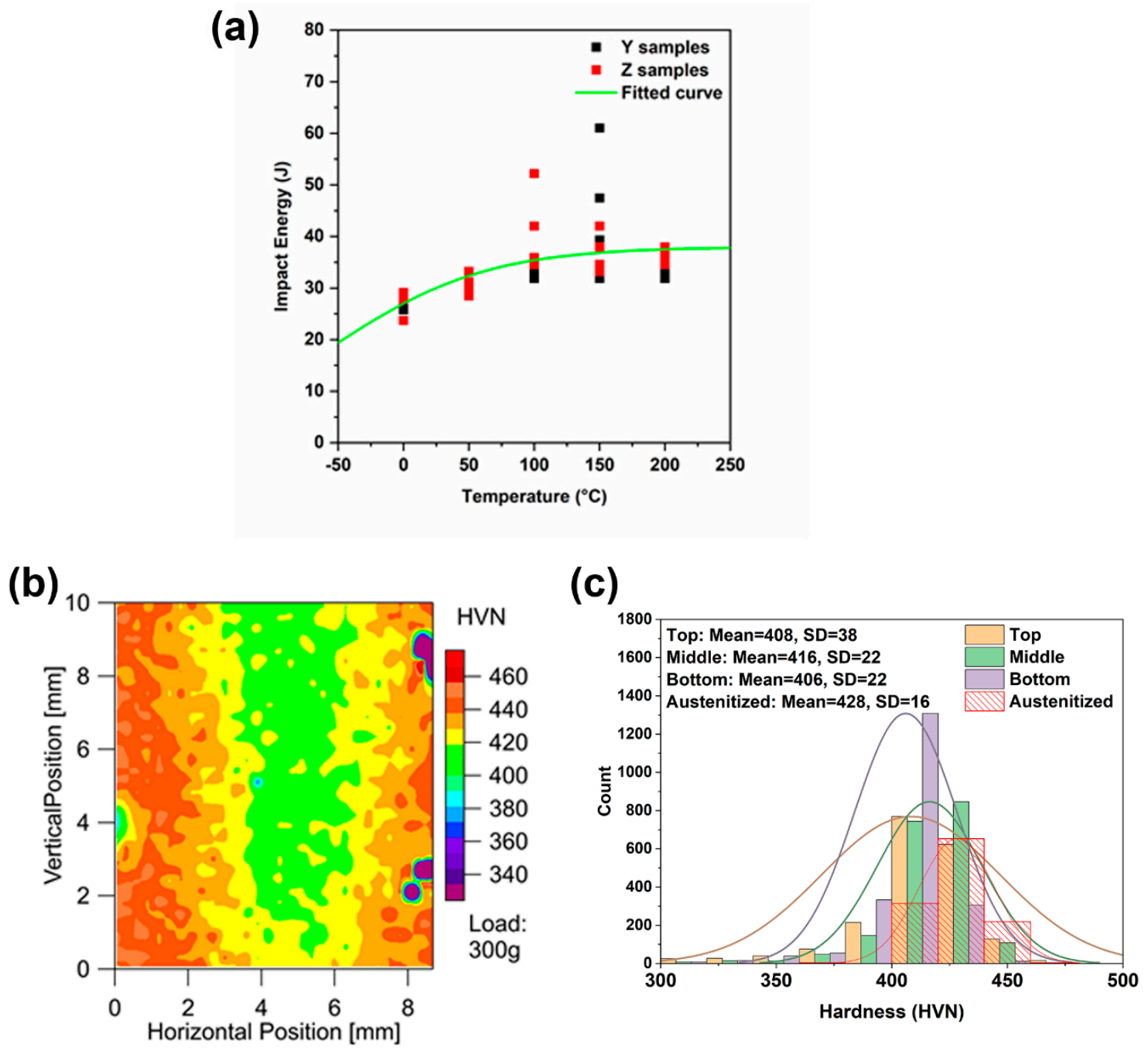

Figure 10. (a) Charpy impact toughness results on austenitized samples sectioned perpendicular $Y$ and parallel $Z$ to build direction, (b) representative hardness map of austenitized samples, and (c) comparative study showing distribution in hardness of austenitized samples against as-printed samples.

Hardness maps were also performed after austenitization (Figure 10b). The hardness map shows a gradual decrease in the hardness from the surface to the core. This is attributed to the fact that the surface cools faster than the core, leading to a finer martensitic microstructure on the surface and progressively decreasing hardness towards the middle of the sample. The histogram values of the hardness results are plotted in Figure 10c and are overlaid with a Gaussian fit of the distribution. The resulting distribution is compared with the distribution obtained in the as-printed samples (top, middle, and bottom regions). The results show a narrower distribution of hardness with a higher mean hardness ( $428 \mathrm{HVN})$ and a smaller standard deviation (16 HVN) compared to the top region of the as-printed samples (mean $408 \mathrm{HVN}$ and standard deviation of $38 \mathrm{HVN}$ ). The increase in the hardness suggests the absence of $\delta$-ferrite, and the decreased standard deviation suggests that the microstructure is homogenous. 


\subsubsection{Microstructural Observations on Austenitized Samples}

Microstructural observation was necessary to validate the hypothesis that was formed based on the tensile test data. Detailed microstructural observations, using SEM and optical imaging, are shown in Figure 11. The microstructure predominantly consisted of an untempered martensite. $\delta$-ferrite was not observed in any of the images captured in three different locations of the build, indicating a successful elimination of $\delta$-ferrite and complete reset of the microstructure. This also corroborated the hypothesis that the elimination of $\delta$-ferrite will improve toughness even when the matrix microstructure is $100 \%$ untempered martensite. A similar observation was previously documented by Carrouge et al., where a martensitic microstructure containing $14 \% \delta$-ferrite had a DBTT $50{ }^{\circ} \mathrm{C}\left(\mathrm{DBTT}\right.$ of $-46{ }^{\circ} \mathrm{C}$ ) higher than a $100 \%$ martensitic microstructure (DBTT of $-98^{\circ} \mathrm{C}$ ) [22]. They also observed that, by reducing the $\delta$-ferrite from $14 \%$ to $2 \%$, it was possible to recover the DBTT to a value close to the parent material. The DBTT of the microstructure with the $2 \% \delta$-ferrite was $\sim 87^{\circ} \mathrm{C}$. This is consistent with the idea that complete elimination of $\delta$-ferrite leads to a drastic improvement in toughness of the 410 stainless steel samples fabricated via a wire-arc-based additive manufacturing.
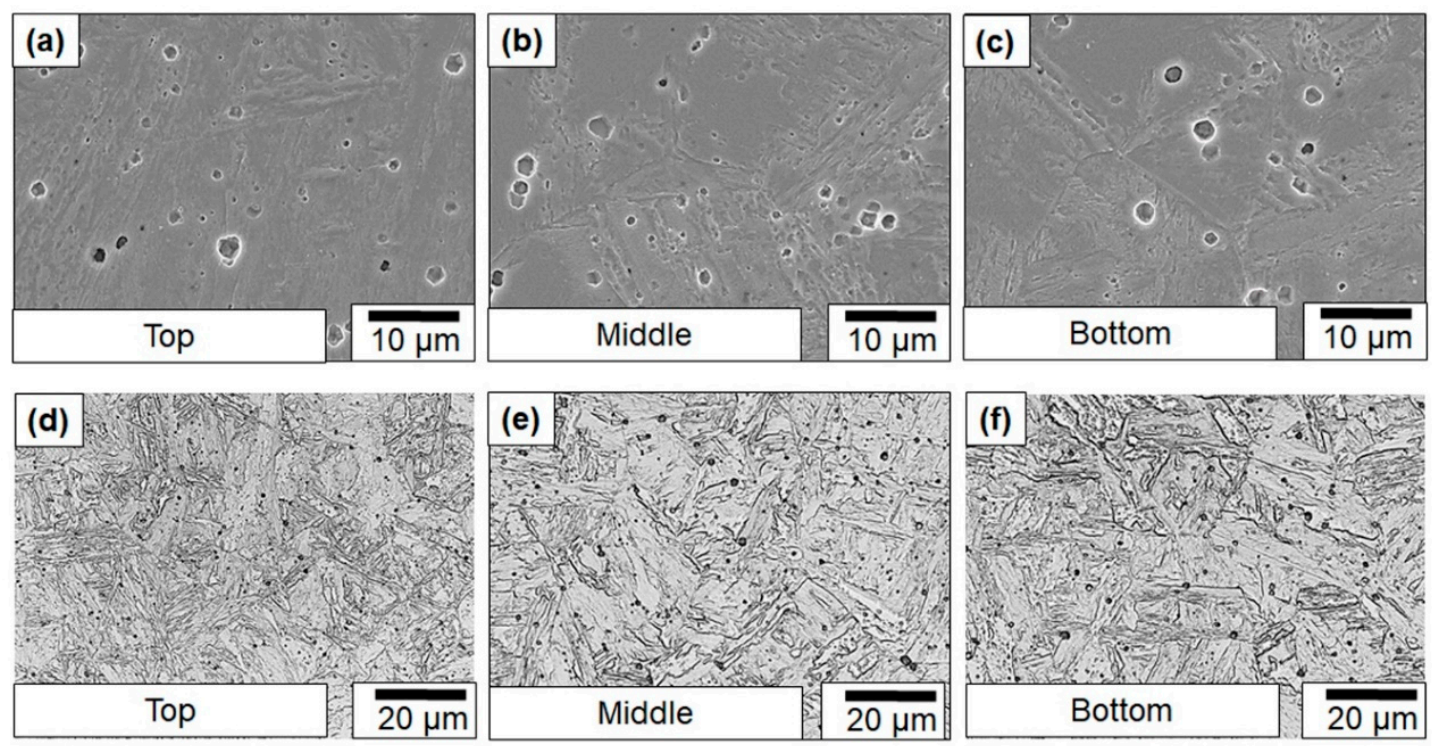

Figure 11. (a-c) Scanning electron and (d-f) optical micrographs of austenitized samples sectioned from the $(\mathbf{a}, \mathbf{d})$ top, $(\mathbf{b}, \mathbf{e})$ middle, and $(\mathbf{c}, \mathbf{f})$ bottom of the wall.

While austenitizing the samples improved the toughness without a loss in hardness, tempering is typically required to further improve the toughness. Tempering also sometimes can help in slightly enhancing hardness, due to the precipitation of alloy carbides [30]. However, the tempering curves for additively manufactured 410 steel are not available and, as pointed out in the literature review section, there is significant uncertainty in the literature regarding the post-tempering embrittlement of martensitic steels. Therefore, a detailed study of the effects of tempering on the hardness and toughness was performed.

\subsubsection{Microstructural Observation on the Tempered Samples}

Since alloy carbides can form in the early stages of tempering in 410 steels, it is reasonable to expect a certain degree of secondary hardening $[30,37]$. To expect further improvement of the toughness, the samples were tempered at temperatures between $350{ }^{\circ} \mathrm{C}$ to $750{ }^{\circ} \mathrm{C}$ in increments of $100{ }^{\circ} \mathrm{C}$. Figure 12 shows the optical microstructure of the as-austenitized samples compared with the selected tempered samples. The optical micrographs clearly show that extensive tempering occurs only at temperatures beyond $550{ }^{\circ} \mathrm{C}$. 

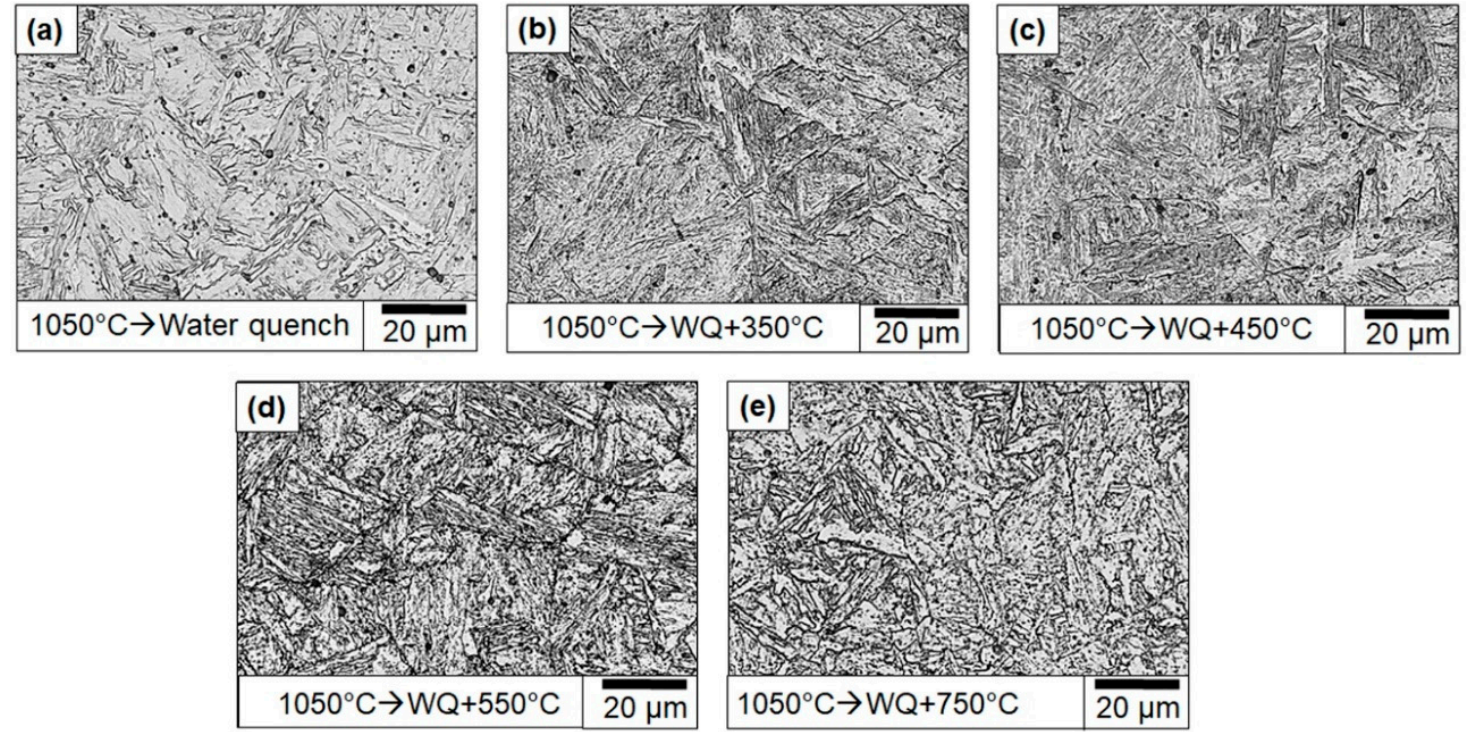

Figure 12. Optical micrographs of (a) austenitized followed by water-quenched and tempered samples with tempering temperature; (b) $350{ }^{\circ} \mathrm{C}$; (c) $450{ }^{\circ} \mathrm{C}$; (d) $550{ }^{\circ} \mathrm{C}$; (e) $750{ }^{\circ} \mathrm{C}$.

To investigate this in more detail, SEM was performed, and the results are shown in Figure 13. Figure 13a shows a graphical representation of increase in precipitate sizes with increase in tempering temperature. The average precipitate size increased significantly when the tempering temperature was $550{ }^{\circ} \mathrm{C}$. While apparent microstructural changes after tempering at $350{ }^{\circ} \mathrm{C}$ have not been identified in an optical microscope, the SEM images clearly show the presence of carbide precipitates in the samples tempered at $350{ }^{\circ} \mathrm{C}$. The insets in Figure $13 \mathrm{~b}, \mathrm{c}$ show higher magnification of the microstructure, clearly demonstrating the presence of carbides in the microstructure. The carbide distribution is homogenous and needle-shaped. Discerning the nature of these carbides using advanced microscopy is a subject of further research and is beyond the scope of this manuscript. The presence of these needle-shaped carbides has been documented in a previous study [30]. The authors identified these carbides as $\mathrm{Fe}_{2} \mathrm{C}$ and associated the formation of $\mathrm{Fe}_{2} \mathrm{C}$ with a drop in toughness, although the exact mechanism of toughness reduction has not been determined. With increasing temperatures, the carbides coarsen and form lenticular or globular carbides, typically $\mathrm{M}_{23} \mathrm{C}_{6}$. While the size distribution of the carbides at tempering between $350-550{ }^{\circ} \mathrm{C}$ is homogenous, at temperatures beyond $550{ }^{\circ} \mathrm{C}$, a bimodal distribution of carbides occurs (Figure 13e,f). The carbides near the prior austenite grain boundary are coarser compared to the carbides in the block boundaries.

EBSD inverse pole figure (IPF) color maps of austenitized and tempered samples are shown in Figure 14, which also illustrates the grain or packet boundaries with a misorientation angle $\geq 15^{\circ}$. The martensite block sizes from EBSD micrographs were also measured using the ImageJ software (NIH, Maryland, USA) and are presented in Table 1. It can be observed that increasing the tempering temperature above $550{ }^{\circ} \mathrm{C}$ resulted in an increase in the martensite block size, while tempering between $350-550{ }^{\circ} \mathrm{C}$ did not contribute to the coarsening of the martensite blocks.

Table 1. Effect of tempering temperature on martensite block size (Here 'WQ' refers to Water Quench and ' $\mathrm{T}$ ' refers to tempering temperature).

\begin{tabular}{ccccccc}
\hline & $\mathbf{1 0 5 0}{ }^{\circ} \mathbf{C}+\mathbf{W Q}$ & $\mathbf{3 5 0} \mathrm{T}$ & $\mathbf{4 5 0} \mathrm{T}$ & $\mathbf{5 5 0} \mathrm{T}$ & $\mathbf{6 5 0} \mathrm{T}$ & $\mathbf{7 5 0} \mathrm{T}$ \\
\hline Avg. block width $(\mu \mathrm{m})$ & $1.4 \pm 0.4$ & $1.7 \pm 0.5$ & $1.7 \pm 0.5$ & $1.7 \pm 0.5$ & $2.2 \pm 0.5$ & $2.3 \pm 0.5$ \\
\hline
\end{tabular}



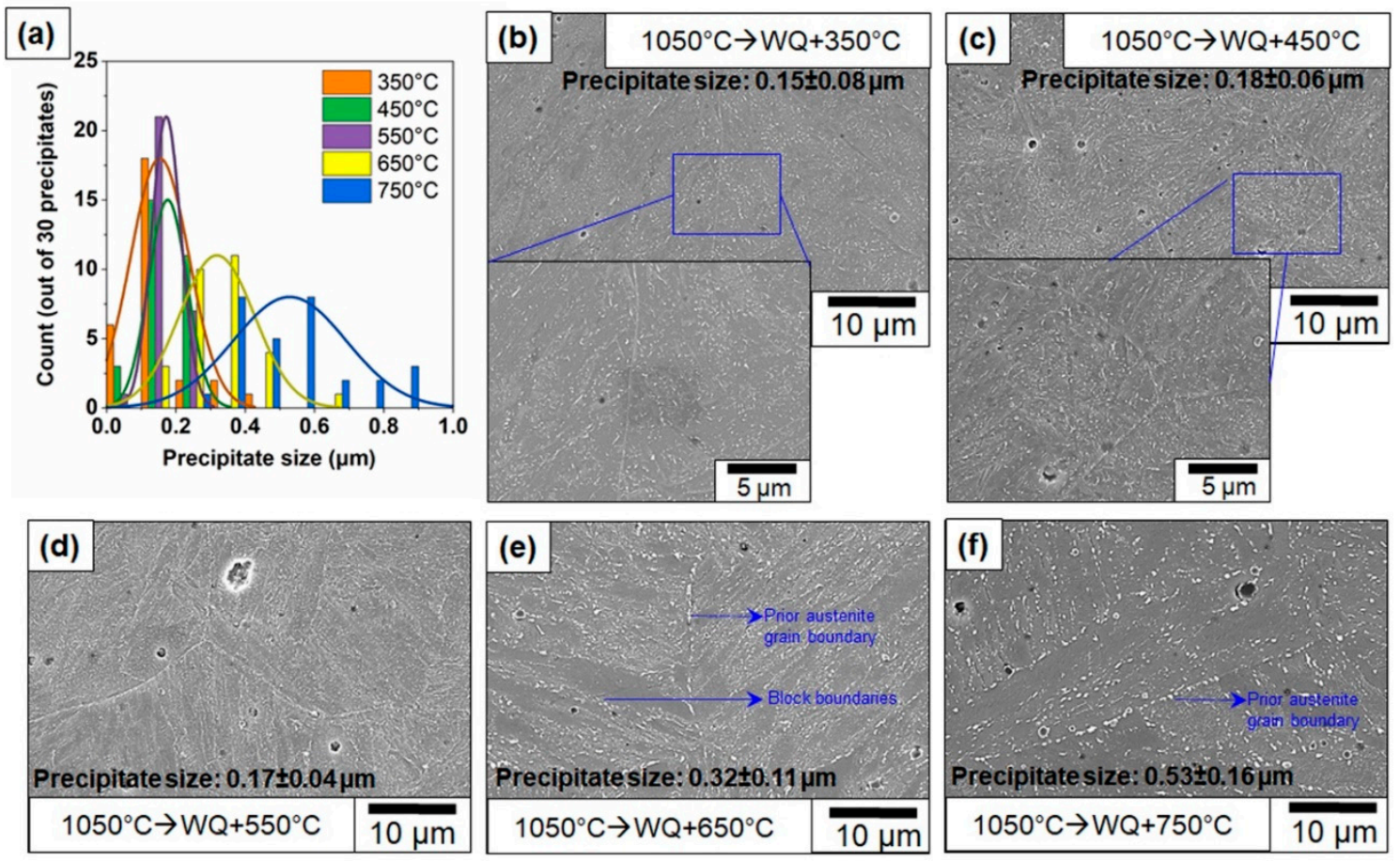

Figure 13. (a) Histogram of precipitate counts in different temperature tempered samples and scanning electron micrographs showing precipitates in samples with tempering temperature; (b) $350{ }^{\circ} \mathrm{C}$; (c) $450{ }^{\circ} \mathrm{C}$; (d) $550{ }^{\circ} \mathrm{C}$; (e) $650{ }^{\circ} \mathrm{C}$; (f) $750{ }^{\circ} \mathrm{C}$.

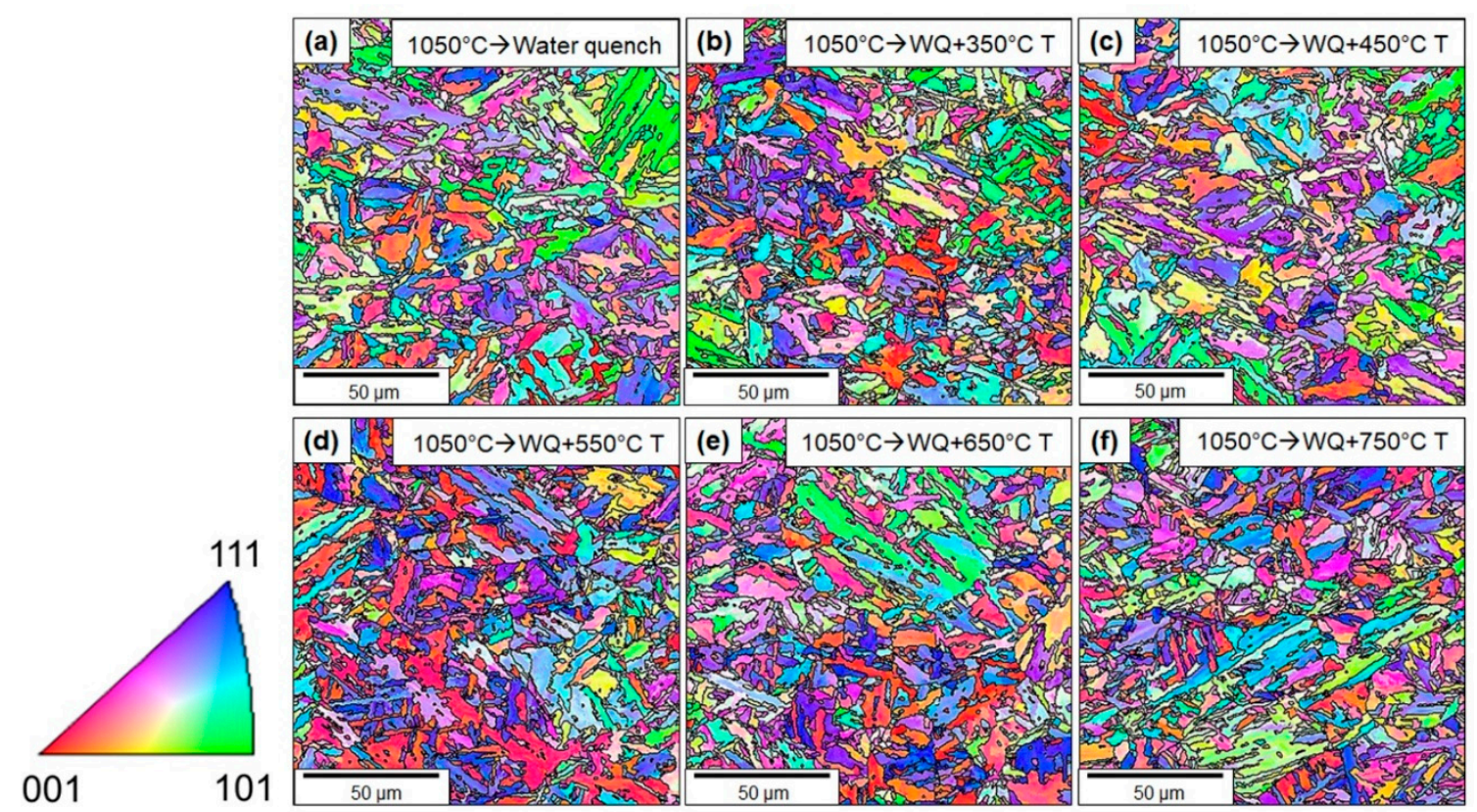

Figure 14. EBSD micrographs of (a) austenitized followed by water-quenched and tempered samples with tempering temperature; (b) $350{ }^{\circ} \mathrm{C}$; (c) $450{ }^{\circ} \mathrm{C}$; (d) $550{ }^{\circ} \mathrm{C}$; (e) $650{ }^{\circ} \mathrm{C}$; (f) $750{ }^{\circ} \mathrm{C}$.

Hardness testing and Charpy toughness testing were performed to determine which tempering treatment achieves the optimum toughness and hardness for tooling fabricated with 410, and the results are discussed in the next section. 


\subsubsection{CVN Toughness and Hardness Measurements on Tempered Samples}

Figure 15a-c shows the results of the Charpy V-notch toughness test that was performed on tempered samples at different temperatures. The samples from three different tempering temperatures $\left(450^{\circ} \mathrm{C}, 550^{\circ} \mathrm{C}\right.$, and $\left.650^{\circ} \mathrm{C}\right)$ were selected for Charpy V-notch tests. Toughness measurements were performed on samples tempered at these temperatures because it has been reported that a significant drop in toughness occurs when tempering between $400-510{ }^{\circ} \mathrm{C}$ [30]. Therefore, temperatures in the middle of that range, just outside the range, and well above the range were selected for further investigations. The samples were tested at $-20^{\circ} \mathrm{C}, 0{ }^{\circ} \mathrm{C}, 22^{\circ} \mathrm{C}, 150{ }^{\circ} \mathrm{C}$, and $200{ }^{\circ} \mathrm{C}$. The changes in the impact toughness at $0^{\circ} \mathrm{C}$ are plotted in Figure $15 \mathrm{~d}$, as a function of the different processing treatments in both the $Z$ and $Y$ directions. In addition, the right-hand axis shows the changes in the Rockwell hardness as a function of the tempering treatment. The data shows a drastic drop in toughness during tempering between the $450-550{ }^{\circ} \mathrm{C}$ in the $Z$ direction. However, the toughness when testing along the $Y$ direction showed a similar drop only for tempering at $550{ }^{\circ} \mathrm{C}$. While the maximum toughness at $0{ }^{\circ} \mathrm{C}$ was obtained after austenitizing and tempering at $650{ }^{\circ} \mathrm{C}$, the hardness values dropped significantly ( 15 HRC). The best-case scenario where the optimum balance between the hardness and toughness can be obtained is austenitizing and tempering at $450{ }^{\circ} \mathrm{C}$. The reason for the anomalous drop in the toughness, specifically for the Z-axis samples, is not understood and is a subject for further research.

(a)

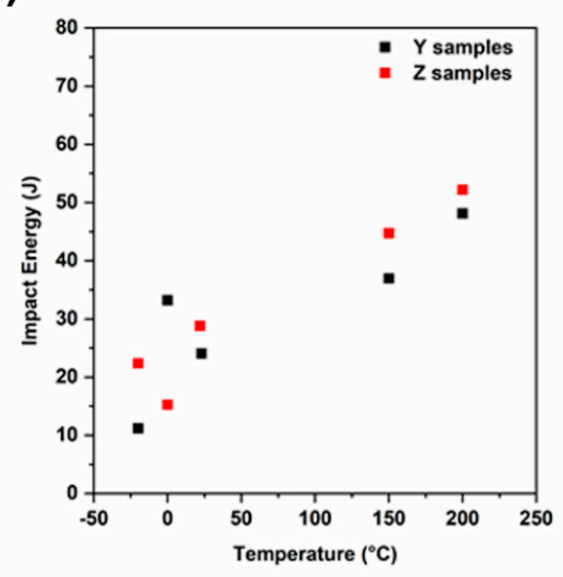

(c)

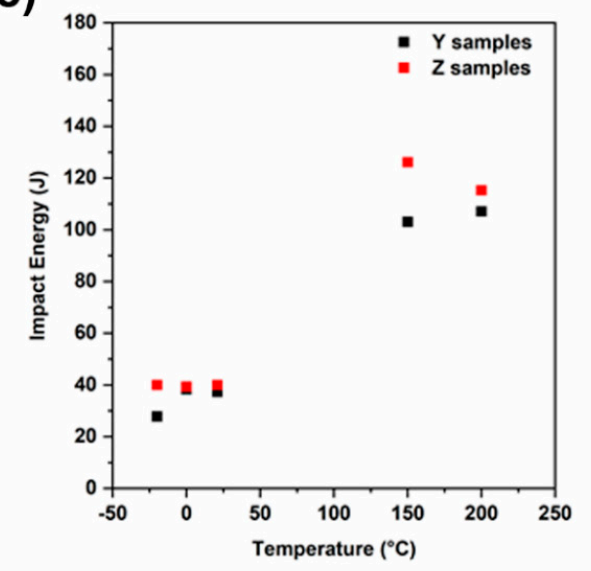

(b)

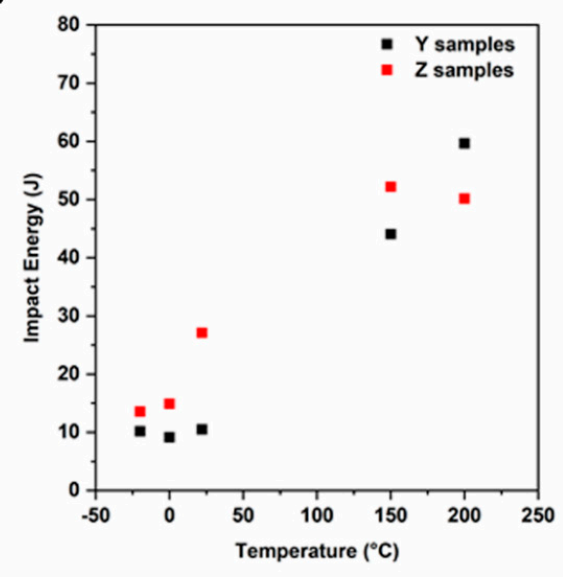

(d)

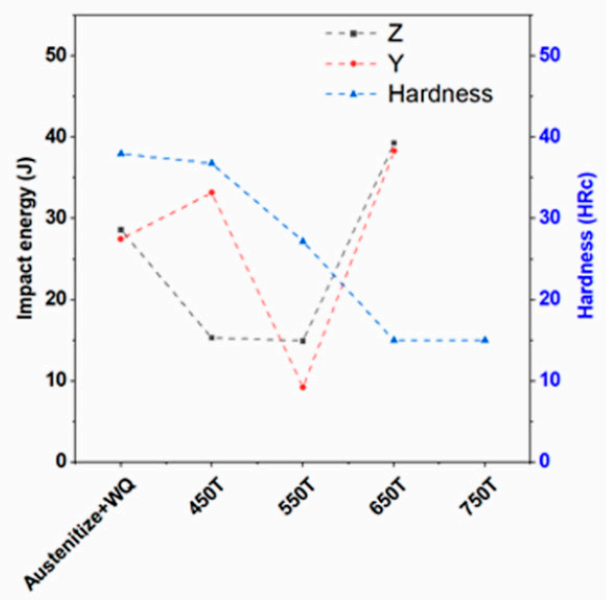

Figure 15. Charpy impact toughness results on samples tempered at (a) $450{ }^{\circ} \mathrm{C}$; (b) $550{ }^{\circ} \mathrm{C}$; (c) $650{ }^{\circ} \mathrm{C}$. (d) Plot showing toughness and hardness of different samples at $0^{\circ} \mathrm{C}$ test temperature. 
This work has attempted to set the stage towards documenting, understanding, and mitigating the challenges of arc-based additive manufacturing of martensitic stainless steels. Mirzaee et al. observed that the toughness of $450{ }^{\circ} \mathrm{C}$ - and $550^{\circ} \mathrm{C}$-tempered wrought 410 steel samples is around $13 \mathrm{~J}$ and $21 \mathrm{~J}$, respectively, at a $-18{ }^{\circ} \mathrm{C}$ test temperature [30]. Metal big-area additively manufactured Z-directional samples tempered at $450{ }^{\circ} \mathrm{C}$ and $550^{\circ} \mathrm{C}$ showed toughness levels of $22 \mathrm{~J}$ and $14 \mathrm{~J}$, respectively, at the $-20{ }^{\circ} \mathrm{C}$ test condition.

\section{Conclusions}

This study systematically documented the scatter in mechanical properties and correlated it to the microstructural heterogeneity in a SS 410 sample fabricated using arc-based additive manufacturing. A solution to mitigate the scatter in those mechanical properties was also presented here.

- The as-fabricated samples showed significant scatter in their properties. The average yield strengths of the as-fabricated condition in $0^{\circ}, 45^{\circ}$, and $90^{\circ}$ oriented samples were $700 \pm 49,879 \pm 40$, and $773 \pm 23 \mathrm{MPa}$, respectively. In addition, there was significant scatter in the toughness values because the samples extracted from the bottom of the build had a higher toughness compared to those present in the top. This has been attributed to the formation of $\delta$-ferrite in the top zone of the build and the smaller amounts of the $\delta$-ferrite in the bottom regions of the build.

- To eliminate the scatter in properties, post-processing heat treatments were employed. Austenitization was performed at $1050{ }^{\circ} \mathrm{C}$ to eliminate the $\delta$-ferrite in the builds. Samples after austenitization showed a significant reduction in the scatter of the toughness and tensile data. Complimentary microscopy and hardness testing indicated that this increase in toughness and reduction in scatter can be attributed to the elimination of $\delta$-ferrite and the homogenization of the microstructure.

- Tempering studies were also conducted on the austenitized specimens, at different temperatures between $350-750{ }^{\circ} \mathrm{C}$, in increments of $100{ }^{\circ} \mathrm{C}$. The studies showed a reduction of toughness while tempering in the $450-550^{\circ} \mathrm{C}$ range. It was also observed that the decrease in toughness was more pronounced in the samples along the $Z$ direction (build direction) compared to the $Y$ direction. This is a subject for future research.

Overall, this study has documented the challenges associated with the scatter in toughness. In addition, it also outlines the opportunities for alloy development efforts within the 410 space. For instance, this study has conclusively shown that the scatter in 410 is primarily driven by the formation of $\delta$-ferrite. Therefore, the alloys used for additive manufacturing should balance alloy composition and deposition parameters to effectively allow primary $\delta$-ferrite to completely transform to austenite during solidification. Of the commercially available martensitic stainless-steel wires, 420 [38] and 410-NiMo [25] can be used to reduce the $\delta$ ferrite formation. In addition, novel compositions can also be designed, using CALPHAD approaches, to create compositions tailored for additive manufacturing.

Author Contributions: Conceptualization, S.R., B.S. and N.S.; Creation of Experimental Builds, L.M. and J.P.; Methodology, Data Collection, Analysis, and Resources S.R., B.S. and J.Y.; Writing-Original Draft Preparation, S.R.; Writing-Review \& Editing, All Authors; Visualization, S.R.; Supervision, A.N, B.K.N., N.S.; Project Administration, M.N.; Funding Acquisition, A.N., and M.N. All authors have read and agreed to the published version of the manuscript.

Funding: This research was funded by US Department of Energy (DOE) Advanced Manufacturing Office (AMO).

Acknowledgments: The Authors would like to thank Sudarsanam Suresh Babu at the University of Tennessee, Knoxville and Yukinori Yamamoto at Oak Ridge National Laboratory for their comments on this study. They are also grateful to Kevin Hanson and Daniel T. Moore at ORNL for their help in heat treatment of SS410 walls. The authors would also like to acknowledge the support of collaborating partners Lincoln Electric, Wolf Robotics on this project and access to wire arc additive manufacturing setup at the Manufacturing Demonstration Facility in Oak Ridge National Laboratory. This research is sponsored by the U.S. Department of Energy, Office of Energy Efficiency and Renewable Energy, Advanced Manufacturing Office, under Contract DE-AC05-00OR22725 with UT-Battelle, LLC. 
Conflicts of Interest: The authors declare no conflict of interest.

\section{References}

1. Bandyopadhyay, A.; Gualtieri, T.; Bose, S. Global Engineering and Additive Manufacturing. In Additive Manufacturing; Informa UK Limited: London, UK, 2015; pp. 1-18.

2. Attaran, M. The rise of 3-D printing: The advantages of additive manufacturing over traditional manufacturing. Bus. Horiz. 2017, 60, 677-688. [CrossRef]

3. Krueger, H. Standardization for Additive Manufacturing in Aerospace. Engineering 2017, 3, 585. [CrossRef]

4. Debroy, T.; Wei, H.; Zuback, J.; Mukherjee, T.; Elmer, J.; Milewski, J.; Beese, A.; Wilson-Heid, A.; De, A.; Zhang, W. Additive manufacturing of metallic components-Process, structure and properties. Prog. Mater. Sci. 2018, 92, 112-224. [CrossRef]

5. Williams, S.W.; Martina, F.; Addison, A.C.; Ding, J.; Pardal, G.; Colegrove, P.A. Wire + Arc Additive Manufacturing. Mater. Sci. Technol. 2016, 32, 641-647. [CrossRef]

6. Hassen, A.A.; Noakes, M.; Nandwana, P.; Kim, S.; Kunc, V.; Vaidya, U.; Love, L.; Nycz, A. Scaling Up metal additive manufacturing process to fabricate molds for composite manufacturing. Addit. Manuf. 2020, 32, 101093. [CrossRef]

7. Nycz, A.; Noakes, M.W.; Richardson, B.; Messing, A.; Post, B.; Paul, J.; Flamm, J.; Love, L. Challenges in Making Complex Metal Large-Scale Parts for Additive Manufacturing: A Case Study Based on the Additive Manufacturing Excavator. In Proceedings of the 28th Annual International Solid Freeform Fabrication Symposium-An Additive Manufacturing Conference, Austin, TX, USA, 7-9 August 2017.

8. Greer, C.; Nycz, A.; Noakes, M.; Richardson, B.; Post, B.; Kurfess, T.; Love, L. Introduction to the design rules for Metal Big Area Additive Manufacturing. Addit. Manuf. 2019, 27, 159-166. [CrossRef]

9. Shassere, B.; Nycz, A.; Noakes, M.W.; Masuo, C.; Sridharan, N. Correlation of Microstructure and Mechanical Properties of Metal Big Area Additive Manufacturing. Appl. Sci. 2019, 9, 787. [CrossRef]

10. Hu, X.; Nycz, A.; Lee, Y.; Shassere, B.; Simunovic, S.; Noakes, M.; Ren, Y.; Sun, X. Towards an integrated experimental and computational framework for large-scale metal additive manufacturing. Mater. Sci. Eng. A 2019, 761, 138057. [CrossRef]

11. Ali, Y.; Henckell, P.; Hildebrand, J.; Reimann, J.; Bergmann, J.; Barnikol-Oettler, S. Wire arc additive manufacturing of hot work tool steel with CMT process. J. Mater. Process. Technol. 2019, 269, 109-116. [CrossRef]

12. Ge, J.; Ma, T.; Chen, Y.; Jin, T.; Fu, H.; Xiao, R.; Lei, Y.; Lin, J. Wire-arc additive manufacturing H13 part: 3D pore distribution, microstructural evolution, and mechanical performances. J. Alloys Compd. 2019, 783, 145-155. [CrossRef]

13. Design Guidelines for Selection and Use of Stainless Steels (9014). Nickel Development Institute (NiDI). Available online: https://nickelinstitute.org/media/1667/ designguidelinesfortheselectionanduseofstainlesssteels_9014_.pdf (accessed on 27 October 2020).

14. Badheka, V.J.; Agrawal, S.K.; Shroff, N. Mode of failure of resistance spot welded martenstic stainless steel-Part II. Int. J. Mech. Mater. Eng. 2010, 5.

15. Kurt, B.; Orhan, N.; Somunkiran, I.; Kaya, M. The effect of austenitic interface layer on microstructure of AISI 420 martensitic stainless steel joined by keyhole PTA welding process. Mater. Des. 2009, 30, 661-664. [CrossRef]

16. Aucott, L.; Huang, D.; Dong, H.; Wen, S.W.; Marsden, J.A.; Rack, A.; Cocks, A.C.F. Initiation and growth kinetics of solidification cracking during welding of steel. Sci. Rep. 2017, 7, 40255. [CrossRef] [PubMed]

17. Dhooge, A.; Vinckier, A. Reheat cracking-A review of recent studies. Int. J. Press. Vessel. Pip. 1987, 27, 239-269. [CrossRef]

18. Lippold, J.C.; Kotecki, D.J. Welding metallurgy and weldability of stainless steels. Choice Rev. Online 2005, 43, 43. [CrossRef]

19. Sridharan, N.; Noakes, M.W.; Nycz, A.; Love, L.; Dehoff, R.R.; Babu, S.S. On the toughness scatter in low alloy C-Mn steel samples fabricated using wire arc additive manufacturing. Mater. Sci. Eng. A 2018, 713, 18-27. [CrossRef]

20. Sridharan, N.; Field, K. A Road Map for the Advanced Manufacturing of Ferritic-Martensitic Steels. Fusion Sci. Technol. 2019, 75, 264-274. [CrossRef] 
21. Sridharan, N.; Gussev, M.; Field, K.G. Performance of a ferritic/martensitic steel for nuclear reactor applications fabricated using additive manufacturing. J. Nucl. Mater. 2019, 521, 45-55. [CrossRef]

22. Carrouge, D.; Bhadeshia, H.; Woollin, P. Effect of $\delta$-ferrite on impact properties of supermartensitic stainless steel heat affected zones. Sci. Technol. Weld. Join. 2004, 9, 377-389. [CrossRef]

23. Castro, R.; Cadanet, J.J.D. Welding Metallurgy of Stainless and Heat-Resisting Steels; Cambridge University Press: Cambridge, UK, 1975.

24. Velázquez-del Rosario, A.; Mariño-Pérez, A.; Mariño-Cala, M. Weldability examination of ASTM A 240 S41500 martensitic stainless steel by thermal cycles simulation testings. Minería y Geología 2015, 31, 80-94.

25. Divya, M.; Das, C.; Ramasubbu, V.; Albert, S.; Bhaduri, A. Improving 410NiMo weld metal toughness by PWHT. J. Mater. Process. Technol. 2011, 211, 2032-2038. [CrossRef]

26. Baghjari, S.; Mousavi, S.A. Effects of pulsed Nd:YAG laser welding parameters and subsequent post-weld heat treatment on microstructure and hardness of AISI 420 stainless steel. Mater. Des. 2013, 43, 1-9. [CrossRef]

27. Divya, M.; Das, C.R.; Albert, S.K.; Ramasubbu, V.; Bhaduri, A.K.; Sivaraman, P. In-situ Weld Repair of Cracked Shrouds of Turbine and Characterization of The Weld Joint. Indian Weld. J. 2011, 44, 49. [CrossRef]

28. Ning, L.; Zhonggang, D.; Menggen, H. Effect of heat treatment on microstructure and mechanical properties of martensitic-ferritic stainless steel containing 17\%Cr and 2\%Ni. Mater. Sci. Technol. 1991, 7, 1057-1062. [CrossRef]

29. Chakraborty, G.; Das, C.R.; Albert, S.; Bhaduri, A.; Paul, V.T.; Panneerselvam, G.; Dasgupta, A. Study on tempering behaviour of AISI 410 stainless steel. Mater. Charact. 2015, 100, 81-87. [CrossRef]

30. Mirzaee, M.; Momeni, A.; Aieni, N.; Keshmiri, H. Effect of quenching and tempering on microstructure and mechanical properties of 410 and $410 \mathrm{Ni}$ martensitic stainless steels. J. Mater. Res. 2017, 32, 687-696. [CrossRef]

31. Bilmes, P.; Solari, M.; Llorente, C. Characteristics and effects of austenite resulting from tempering of 13Cr-NiMo martensitic steel weld metals. Mater. Charact. 2001, 46, 285-296. [CrossRef]

32. Standards ASTM International. E28 Committee Test Methods for Tension Testing of Metallic Materials; Standards ASTM International: West Conshohocken, PA, USA, 2016. [CrossRef]

33. Standards ASTM International. ASTM E 23-12c, Standard Test Methods for Notched Bar Impact Testing of Metallic Materials; Standards; Standards ASTM International: West Conshohocken, PA, USA, 2013. [CrossRef]

34. Bösing, I.; Cramer, L.; Steinbacher, M.; Zoch, H.-W.; Thöming, J.; Baune, M. Influence of heat treatment on the microstructure and corrosion resistance of martensitic stainless steel. AIP Adv. 2019, 9, 065317. [CrossRef]

35. Kim, H.J.; Kim, Y.H.; Morris, J.J.W. Thermal Mechanisms of Grain and Packet Refinement in a Lath Martensitic Steel. ISIJ Int. 1998, 38, 1277-1285. [CrossRef]

36. Krauss, G. Fine structure of austenite produced by the reverse martensitic transformation. Acta Met. 1963, 11, 499-509. [CrossRef]

37. Dossett, J.L.; Totten, G.E. (Eds.) Volume 4D: Heat Treating of Iron and Steels; ASM Handbook, ASM International: Materials Park, OH, USA, 2014.

38. Köse, C.; Kaçar, R. The effect of preheat \& post weld heat treatment on the laser weldability of AISI 420 martensitic stainless steel. Mater. Des. 2014, 64, 221-226. [CrossRef]

Publisher's Note: MDPI stays neutral with regard to jurisdictional claims in published maps and institutional affiliations.

(C) 2020 by the authors. Licensee MDPI, Basel, Switzerland. This article is an open access article distributed under the terms and conditions of the Creative Commons Attribution (CC BY) license (http://creativecommons.org/licenses/by/4.0/). 